\title{
Procesos de gestión de los proyectos de inversión de infraestructura vial en los gobiernos regionales: un caso del gobierno regional de San Martín - Perú
}

\author{
Juana Maribel Lavado Enriquez \\ Maribellavado_jm@hotmail.com \\ Dr. Keller Sánchez Dávila \\ Ssanchezda2081@ucvvirtual.edu.pe \\ Universidad César Vallejo
}

\section{RESUMEN}

La investigación se planteó con el objetivo general de analizar los Procesos de gestión de los Proyectos de Inversión de Infraestructura Vial en los Gobiernos Regionales: Un caso el Gobierno Regional de San Martín. El tipo de estudio es básico, el diseño de la investigación es descriptivo, con un enfoque cualitativo mediante la revisión sistemática. La población fue de 1454 artículos y la muestra estuvo conformada por 21 artículos relevantes de revistas indexadas. La técnica fue la guía de revisión bibliográfica y el instrumento fue la tabla de análisis. Entre los resultados, tenemos que las inversiones en la infraestructura vial incrementan el desarrollo económico, pero presentan vulnerabilidad por la actitud en los manejos políticos de los gobernantes de turno, para alcanzar la sostenibilidad vial es dar las mismas oportunidades a la economía, el medio ambiente y la sociedad. Los proyectos de inversión y la gestión de valor buscan la participación de todos los grupos de interés, para garantizar el éxito del proyecto. Los desarrollos económicos son graduales en las regiones y tienen un impacto positivo con la inversión en infraestructura de transporte para lograr la eficiencia y el nivel de competitividad. Así, mismo la gestión por procesos es una exigencia de alineación a la estrategia que buscan la transformación y la incorporación de valor de las organizaciones, esto se da con la implementación de los procesos en las instituciones responsables y competitivas para lograr la eficiencia y la sostenibilidad de las sociedades futuras. Concluyendo, que aún faltan cerrar las brechas de los proyectos de infraestructura vial y la implementación de los procesos en la organización, por la cual se necesita del compromiso de todos los grupos de interés.

Palabras clave: procesos de gestión; proyectos de inversión; infraestructura vial; desarrollo económico. 


\title{
Management processes and road infrastructure investment projects in the regional governments: a case of the regional government of San Martín - Peru
}

\begin{abstract}
The investigation was raised with the general objective of analyzing the Management Processes of the Road Infrastructure Investment Projects in the Regional Governments: A case the Regional Government of San Martín. The type of study is basic, the research design is descriptive, with a qualitative approach through systematic review. The population was 1,454 articles and the sample consisted of 21 relevant articles from indexed journals. The technique was the bibliographic review guide and the instrument was the analysis table. Among the results, we have that investments in road infrastructure increase economic development, but present vulnerability due to the attitude in the political management of the current rulers, to achieve road sustainability is to give the same opportunities to the economy, the environment and society. Investment projects and value management seek the participation of all stakeholders, to guarantee the success of the project. Economic developments are gradual in the regions and have a positive impact with investment in transport infrastructure to achieve efficiency and the level of competitiveness. Likewise, process management is a requirement of alignment to the strategy that seeks to transform and add value to organizations, this occurs with the implementation of processes in responsible and competitive institutions to achieve efficiency and sustainability. of future societies. In conclusion, the gaps in road infrastructure projects and the implementation of the processes in the organization have yet to be closed, which requires the commitment of all stakeholders.
\end{abstract}

Keywords: management processes; investment projects; road infrastructure; economic development.

Artículo recibido: 18. Julio. 2021

Aceptado para publicación: 08. Agosto. 2021 Correspondencia: Maribellavado_jm@ hotmail.com

Conflictos de Interés: Ninguna que declarar 


\section{INTRODUCCIÓN}

Según los países de la Unión Europea (UE), la inversión de la Infraestructura Vial tiene en cuenta los Procesos de Gestión, seguidos de la toma de decisiones integrales e inclusivas lo que significa que cubre las tres dimensiones como son la ambiental, social y económica; pilares del desarrollo vial sostenible y tienen una función vital en la mejora del crecimiento regional y la competitividad económica, en especial de los países en desarrollo; pero los aspectos ambientales se descuidan relativamente y la ambición política desempeña un rol positivo o negativo en la planificación de proyectos viales (Suprayoga, Bakker, \& Spit, 2020). En efecto, Serrano y García (2017), refieren que en España las inversiones públicas en la infraestructura vial a veces sufren pronunciadas caídas debido a las crisis económicas de los países, por lo que se realizan reajustes significativas en los proyectos viales, trayendo consigo numerosos arrastres negativos como aminorar un ciclo de actividad inversora expansiva; en este caso la continuidad en las inversión viales se da porque es una manera de sostener el crecimiento económico, debido a que no es fácil encontrar otras alternativas de reemplazo.

Por otro lado, el CAF - Banco de Desarrollo de América Latina (2020), desembolso un monto de $\$ 723$ millones para ayudar a la reactivación económica del gobierno del Perú, estos serán asignados a atender las secuelas ocasionados por el Covid 19, con la inversión en la mejora del nivel de servicio de accesibilidad de la red vial subnacional, reducir el tiempo de viaje y los gastos de movilización con la finalidad de incrementar la competitividad nacional y la promoción de trabajo en las provincias. En consecuencia, en el Perú la inversión pública en infraestructura vial es uno de los aspectos poco relevantes de las políticas de los gobernantes de turno, para la gran mayoría de los especialistas la brecha existente en la red vial constituye una dificultad para alcanzar ventajas competitivas, alto desarrollo económico y la inserción eficaz de políticas de desarrollo para llegar a índices de auge económico que superen los estándares internacionales, imposibilitando el desarrollo de un país o región. Por tanto, se tuvo el déficit del 9,1\% de la inversión pública en el 2020, debido a las prevenciones aplicadas para contrarrestar la crisis sanitaria, el Ministerio de Economía y Finanzas del Perú proyecta un crecimiento del 35\%, con la ejecución en el 2021, de S/39.112 millones en obras, siendo hasta la fecha una cifra histórica presupuestal, distribuidos en el gobierno central con un gasto del $57 \%$ del presupuesto toral, haciendo la comparaciones 
es un aumento de $46 \%$ con relación al 2020 (más de S/7.100 millones) y de $26 \%$ con referencia del 2019 (más de S/4.700 millones); también los gobiernos regionales gastaran S/7.140 millones (un incremento de 20\%) y por último los gobiernos locales S/12.963 millones (un aumento de 14,8\%); los objetivos propuestas para los gobiernos sub nacionales son factibles, pero a diferencia del gobierno central se refleja un monto elevado, evidenciando las brechas presupuestales existentes entre la distribución de los recursos en las regiones (Gestión, 2021). De acuerdo al Plan Nacional de Infraestructura para la Competitividad del Perú (2019), depende en gran medida de la accesibilidad vial y de la calidad de servicio, potenciar estos elementos aumenta la conectividad con los mercados nacionales e internacionales, impulsando el desarrollo del recurso humano; aminorar los gastos de transporte de carga, acceso adecuados a colegios y postas de salud, interactuando con los centros productivos elevando el nivel de competitividad (p. 4 - 5).

Por esta razón, según la Resolución de Secretaría de Gestión Pública No 006-2018PCM/SGP (2018), se aprueba la Norma Técnica $N^{\circ}$ 001-2018-SGP para la implementación de la Gestión por Procesos en las instituciones de la administración pública en el Gobierno Peruano y es un instrumento de gestión que ayuda con la ejecución gradual de las metas organizacionales con los recursos que se tiene y así generar impactos positivos en la sociedad; la Norma técnica está basada en la Ley Marco de Modernización del Estado, con el fin de abarcar las demandas y necesidades de los ciudadanos, por ende requiere del involucramiento de los grupos de interés y de la participación de los jefes, el componente de los procesos de gestión agiliza las inversiones de los proyectos de Infraestructura Vial. Particularmente, el Plan Vial Departamental Participativo de la Región San Martín (2012-2021), tiene como objetivo primordial alcanzar una eficiente y eficaz dirección de los recursos presupuestados a la red vial, dirigidos a obtener la integración territorial, de los circuitos de desarrollo económico y social, procurando la accesibilidad y seguridad. En este marco, el Portal de Transparencia Económica del MEF (2021), el Presupuesto Institucional Modificado (PIM) destinado al Gobierno Regional de San Martín es de S/. 1,512,018,532, la ejecución del gasto al 22 de julio del 2021, es de S/. 726,363,360 que equivale al 48\% y el presupuesto asignado para los proyectos de inversión en infraestructura vial es de S/. 67,973,685 el porcentaje gastado es de 28,190,269 que equivale a un $42 \%$. 
Actualmente, se orienta a la búsqueda de información relevante para su aplicación y que permitan efectuar un estudio de la realidad de los países de America del Norte, Latinoamérica y, como se presentan las variables, permitiendo de esta manera reforzar su conceptualización y metodología. La investigación contribuye en la obtención de nueva información para ser aplicados a la sociedad, de igual manera contribuyen a proporcionar nuevos enfoques. Además, los resultados permitirán homogenizar los factores y establecer relaciones entre ellos.

\section{Formulación del problema}

- ¿Cuáles son los procesos de gestión de los proyectos de inversión de infraestructura vial?

\section{Objetivo}

- Analizar los procesos de gestión de los proyectos de inversión de infraestructura vial.

\section{ESTRATEGIAS METODOLÓGICAS O MATERIALES Y MÉTODOS}

\section{El diseño de estudio}

En este sentido, el tipo de estudio es básico porque es una investigación que no cambia la esencia conocida también como pura, y a partir de sus hallazgos se encuentran nuevas teorías científicas. El diseño de la investigación es descriptivo, donde se explican las variables con el análisis bibliográfico de los artículos. Tiene un enfoque cualitativo, mediante la revisión sistemática que nos permite recoger, elegir, analizar críticamente y resumir todas las evidencias disponibles de múltiples artículos científicos en los últimos 5 años, describiendo los resultados para el desarrollo de la discusión, conclusiones y recomendaciones de la investigación. La técnica de la investigación fue la guía de revisión bibliográfica y el instrumento usado es la tabla de análisis bibliográficos.

\section{Procedimiento de recolección de datos.}

Es así que el procedimiento de recolección de datos se realizó con una búsqueda electrónica de artículos científicos para obtener las informaciones relevantes de la investigación, se usó criterios de elegibilidad como los tipos de participantes donde se incluyeron artículos de adultos, personas mayores y servidores públicos en las instituciones, excluyendo las revisiones de investigación teórica: para la recolección de los tipos de estudios se tuvo en cuenta el número limitado de estudios sobre procesos de gestión y proyectos de inversión de infraestructura vial, para trazar una ruta de los 
conocimientos existentes sobre el tema y detectar los diseños de estudios por la relevancia de las pruebas; los tipos de resultados primarios son casuísticas, investigaciones empíricas, experiencias y similares; se ejecutó una búsqueda de estudios utilizando las referencias de los estudios primarios encontrados en la búsqueda electrónica de la base de datos Scopus, SciELO, Redalyc y Google académico, la selección de estudios fueron realizados por una revisora independiente y cualquier divergencia fue resuelta por un segundo revisor; los estudios se seleccionaron en dos etapas: el primer paso, residió en chequear los títulos y abstract de las bibliografías seleccionadas con la búsqueda sistemática, se seleccionaron los estudios potencialmente elegibles y el segundo paso, consistió en revisar el texto total de los estudios preestablecidos para constatar su elegibilidad. En este marco el instrumento que se usó para recolección de bibliografía especializada son las tablas de análisis.

Por otro lado, para la extracción de datos se realizó un diagrama del proceso que se realizó para obtener los artículos seleccionados.

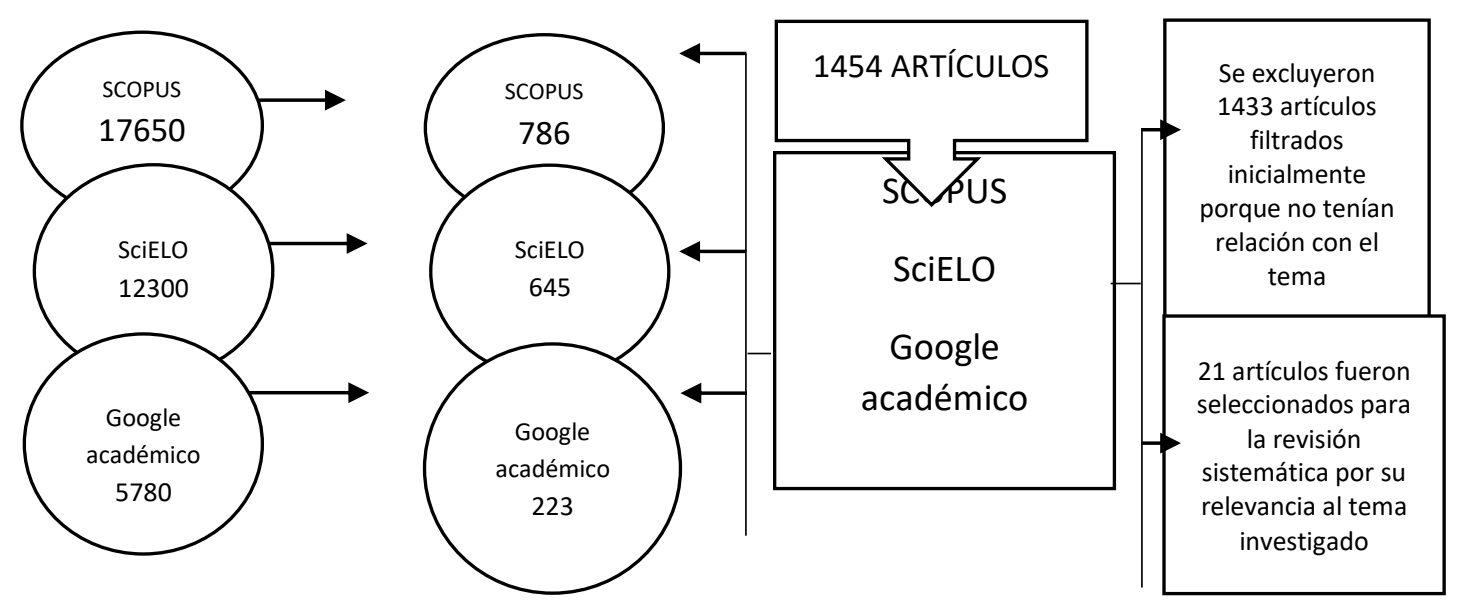

\section{Técnica de análisis.}

En efecto, la técnica del análisis de datos se realizó mediante la revisión sistemática y se usó las tablas de análisis con el propósito de comparar los resultados de las variables de estudio a nivel internacional, nacional y regional de los artículos importantes de la investigación, para realizar el proceso de discusión de los resultados que nos servirán para realizar las conclusiones y recomendaciones finales del estudio. Por otro lado, se cumplió con la integridad científica las fuentes utilizadas para el estudio han sido citadas de acuerdo a las normas internacionales APA, evitando el plagio de la información.

\section{RESULTADOS.}


Por tanto, los resultados se realizaron mediante tablas de análisis, teniendo en cuenta artículos de revistas indexadas a nivel internacional, nacional referente a las variables de estudio de la siguiente forma: 


\subsection{Estudios revisados de proyectos de Inversión de Infraestructura Vial.}

\section{DATOS DE LA PUBLICACIÓN}

\begin{tabular}{|c|c|c|c|c|}
\hline Autor & Año & Nombre de la Investigación & Revista donde se ubica la publicación & Volumen y número \\
\hline Suslov, V.I. , & $(2021)$ & Ценовые аспекты оценки инвестиционных проектов. & https://doi.org/10.17059/ekon.reg.2021-1- & Vol.17, pp. $16-30$ \\
\hline Novikova, T. S. & & & 2 & 2021 \\
\hline , Gulakova, O. I. & & $\begin{array}{l}\text { (Aspectos de precios de la evaluación de proyectos de } \\
\text { inversión) }\end{array}$ & Revista: Economy of Región & \\
\hline
\end{tabular}

\begin{tabular}{|c|c|c|c|c|c|}
\hline \multicolumn{6}{|c|}{ CONTENIDO DE LA PUBLICACIÓN } \\
\hline $\begin{array}{l}\text { Tipo y Diseño de } \\
\text { Investigación }\end{array}$ & Población y Muestra & Instrumentos & $\begin{array}{l}\text { Aspectos } \\
\text { éticos }\end{array}$ & Resultados & Conclusión \\
\hline $\begin{array}{l}\text { Diseño: } \\
\text { Descriptivo. } \\
\text { Tipo: } \\
\text { Comparativo. }\end{array}$ & $\begin{array}{l}\text { Modelo: caso de China, } \\
\text { caso de Corea del Sur y } \\
\text { caso Japón. }\end{array}$ & $\begin{array}{l}\text { Ficha de recojo } \\
\text { de datos. }\end{array}$ & No refiere. & $\begin{array}{l}\text { Los efectos de los precios a partir de cálculos para } \\
\text { un modelo complejo, incluidos modelos financieros } \\
\text { y económicos, intersectoriales, multirregionales y } \\
\text { econométricos se definen en términos de cuatro } \\
\text { grupos principales: comerciales, indirectos, fiscales } \\
\text { y externalidades; para la evaluación de proyectos de } \\
\text { inversión. }\end{array}$ & $\begin{array}{l}\text { Los proyectos regionales } \\
\text { con una presentación } \\
\text { ampliada de proyectos } \\
\text { económicos aumenta la } \\
\text { validez de la evaluación } \\
\text { de proyectos de } \\
\text { infraestructura } \\
\text { inversión, teniendo en } \\
\text { cuenta los efectos de los } \\
\text { precios como un factor } \\
\text { importante en la } \\
\text { diferencia entre }\end{array}$ \\
\hline & & & & & $\begin{array}{l}\text { eficiencia social y } \\
\text { comercial. }\end{array}$ \\
\hline
\end{tabular}




\section{DATOS DE LA PUBLICACIÓN}

\begin{tabular}{|c|c|c|c|c|}
\hline Autor & Año & Nombre de la Investigación & $\begin{array}{l}\text { Revista donde se ubica la } \\
\text { publicación }\end{array}$ & Volumen y número \\
\hline $\begin{array}{l}\text { Sai Avinash, G., } \\
\text { Arora, J. }\end{array}$ & $(2019)$ & $\begin{array}{l}\text { Financias impediments to road infrastructure development in } \\
\text { india. } \\
\text { (Impedimentos financieros para la infraestructura vial desarrollo } \\
\text { en India). }\end{array}$ & $\begin{array}{l}\text { https://doi.org/0.35940/ijitee.K107 } \\
\text { 2.09811S19 } \\
\text { Revista: International Journal of } \\
\text { Innovative Technology and } \\
\text { Exploring Engineering. }\end{array}$ & $\begin{array}{l}\text { vol. 8, pp. } 405-415 \text {, } \\
\text { Setiembre, } 2019\end{array}$ \\
\hline
\end{tabular}

CONTENIDO DE LA PUBLICACIÓN

\begin{tabular}{|c|c|c|c|c|c|}
\hline $\begin{array}{l}\text { Tipo y Diseño de } \\
\text { Investigación }\end{array}$ & Población y Muestra & Instrumentos & $\begin{array}{l}\text { Aspectos } \\
\text { éticos }\end{array}$ & Resultados & Conclusión \\
\hline $\begin{array}{l}\text { Diseño: } \\
\text { Cualitativo y } \\
\text { cuantitativo. } \\
\text { Tipo: } \\
\text { Comparativo. }\end{array}$ & $\begin{array}{l}\text { Modelo: caso de } \\
\text { Proyecto de la autopista } \\
\text { Raipur Bilaspur, el caso } \\
\text { del Proyecto de la } \\
\text { carretera Six } \\
\text { Gundugolanu } \\
\text { Rajahmundry, el caso } \\
\text { del Proyecto de la } \\
\text { carretera } \\
\text { Bhiwani } 4 \text { Larnaul } \\
\text { Patiala, el caso del } \\
\text { proyecto Bathinda } 4 \\
\text { Lane Road. }\end{array}$ & Entrevista. & No refiere. & $\begin{array}{l}\text { El gobierno y las organizaciones de infraestructura } \\
\text { vial deben cooperar para compartir los riesgos } \\
\text { correctamente en las asociaciones públicas y } \\
\text { privadas - APP en las que se asocian en proyectos } \\
\text { complejos de desarrollo vial. El curso de acción del } \\
\text { riesgo compartido debe lograr el equilibrio } \\
\text { adecuado, con la parte mejor preparada es difícil } \\
\text { lograr el crecimiento y desarrollo previstos. }\end{array}$ & $\begin{array}{l}\text { La infraestructura en la } \\
\text { India empieza a pensar } \\
\text { en ella como una } \\
\text { oportunidad de inversión } \\
\text { viable y sostenible. En } \\
\text { consecuencia, la gestión } \\
\text { de proyectos de } \\
\text { desarrollo } \\
\text { infraestructura vial es } \\
\text { fundamental en este } \\
\text { punto. }\end{array}$ \\
\hline
\end{tabular}


DATOS DE LA PUBLICACIÓN

\begin{tabular}{|c|c|c|c|c|}
\hline Autor & Año & Nombre de la Investigación & $\begin{array}{c}\text { Revista donde se ubica la } \\
\text { publicación }\end{array}$ & Volumen y número \\
\hline $\begin{array}{l}\text { Suprayoga, G. } \\
\text { B., Bakker, M., } \\
\text { Witte, P., Spit, } \\
\text { T. }\end{array}$ & $\begin{array}{l}\text { (202 } \\
0)\end{array}$ & $\begin{array}{l}\text { A systematic review of indicators to assess the sustainability of } \\
\text { road infrastructure projects. } \\
\text { (Una revisión sistemática de indicadores para evaluar la } \\
\text { sostenibilidad de los proyectos de infraestructura vial). }\end{array}$ & $\begin{array}{l}\text { https://doi.org/10.1186/s12544- } \\
\text { 020-0400-6 } \\
\text { Revista: European Transport } \\
\text { Research Review }\end{array}$ & $\begin{array}{l}\text { vol. 12, pp. } 1 \text { - } 15 \text {, } \\
\text { núm.19, Diciembre, } 2020\end{array}$ \\
\hline
\end{tabular}

\section{CONTENIDO DE LA PUBLICACIÓN}

\begin{tabular}{|c|c|c|c|c|c|}
\hline $\begin{array}{l}\text { Tipo y Diseño de } \\
\text { Investigación }\end{array}$ & $\begin{array}{c}\text { Población y } \\
\text { Muestra }\end{array}$ & Instrumentos & $\begin{array}{l}\text { Aspectos } \\
\text { éticos }\end{array}$ & Resultados & Conclusión \\
\hline $\begin{array}{l}\text { Diseño: } \\
\text { Cualitativo y } \\
\text { cuantitativo } \\
\text { Tipo: } \\
\text { Comparativo. }\end{array}$ & $\begin{array}{l}31 \text { artículos de los } \\
\text { países europeos, a } \\
\text { saber, Alemania, } \\
\text { Reino Unido, } \\
\text { España, Francia, } \\
\text { Dinamarca, Croacia, } \\
\text { Polonia y Hungría. } \\
\text { Los países de } \\
\text { América del Norte. }\end{array}$ & $\begin{array}{l}\text { Ficha de recojo } \\
\text { de datos. }\end{array}$ & $\begin{array}{l}\text { No conflicto } \\
\text { de interés. }\end{array}$ & $\begin{array}{l}\text { Los proyectos son un enfoque prometedor, y cubre } \\
\text { criterios de saber, adaptación y precaución y equidad } \\
\text { intergeneracional En proyectos de transporte, la } \\
\text { sostenibilidad evalúa si un proyecto "Contribuye a } \\
\text { favorecer el desarrollo económico y a satisfacer las } \\
\text { necesidades de transporte de la sociedad de manera } \\
\text { coherente con los valores ecológicos y humanos", es } \\
\text { una metodología avanzada para garantizar que la } \\
\text { toma de decisiones sea integral e inclusiva, lo que } \\
\text { significa que cubre las tres dimensiones / pilares del } \\
\text { desarrollo sostenible (es decir, las dimensiones } \\
\text { ambiental, social y económica), incluidos los efectos } \\
\text { indirectos. La ambición política puede desempeñar } \\
\text { un papel fundamental en la planificación de } \\
\text { proyectos viales. Los proyectos tienen una función } \\
\text { vital en la mejora del crecimiento regional y la } \\
\text { competitividad económica, especialmente en los } \\
\text { países en desarrollo. Sin embargo, los aspectos } \\
\text { ambientales se descuidan relativamente. }\end{array}$ & $\begin{array}{l}\text { La infraestructura vial de } \\
\text { la Unión Europea (UE) } \\
\text { muestran que la } \\
\text { sostenibilidad de los } \\
\text { proyectos de } \\
\text { infraestructura vial no es } \\
\text { solo una cuestión de } \\
\text { despliegue técnico de los } \\
\text { enfoques, sino también un } \\
\text { proceso integrado de toma } \\
\text { de decisiones. Por lo } \\
\text { tanto, para mejorar la } \\
\text { efectividad, no solo deben } \\
\text { avanzarse los enfoques, } \\
\text { sino que también deben } \\
\text { identificarse los procesos } \\
\text { y las barreras } \\
\text { contextuales. }\end{array}$ \\
\hline
\end{tabular}




\section{DATOS DE LA PUBLICACIÓN}

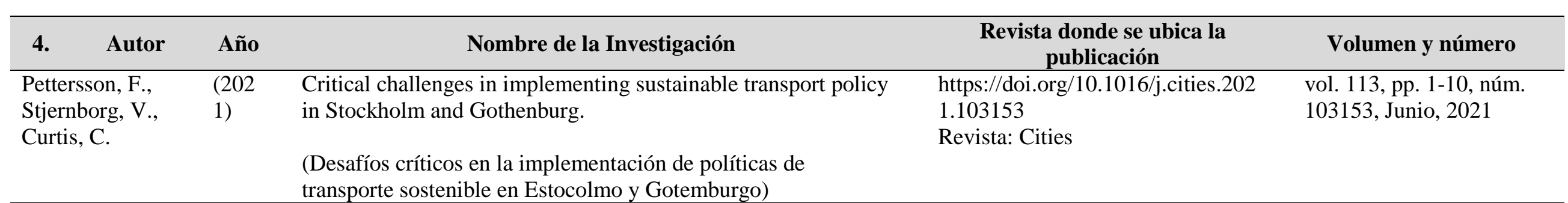

transporte sostenible en Estocolmo y Gotemburgo)

\begin{tabular}{|c|c|c|c|c|c|}
\hline \multicolumn{6}{|c|}{ CONTENIDO DE LA PUBLICACIÓN } \\
\hline $\begin{array}{l}\text { Tipo y Diseño de } \\
\text { Investigación }\end{array}$ & $\begin{array}{c}\text { Población y } \\
\text { Muestra }\end{array}$ & Instrumentos & $\begin{array}{l}\text { Aspectos } \\
\text { éticos }\end{array}$ & Resultados & Conclusión \\
\hline $\begin{array}{l}\text { Diseño: } \\
\text { Cualitativo y } \\
\text { cuantitativo. } \\
\text { Tipo: } \\
\text { Comparativo. }\end{array}$ & $\begin{array}{l}\text { Modelo: caso de } \\
\text { gobierno de Suecia } \\
\text { con sus dos ciudades } \\
\text { Estocolmo y } \\
\text { Gotemburgo. }\end{array}$ & Entrevista. & $\begin{array}{l}\text { No conflicto } \\
\text { de interés. } \\
\text {. }\end{array}$ & $\begin{array}{l}\text { Los modelos mentales de los planificadores suecos } \\
\text { apoyan los ideales del transporte sostenible. } \\
\text { Centrándose en tres desafíos críticos: planificación } \\
\text { basada en pronósticos versus planificación basada en } \\
\text { visión; abordar la congestión; y aceptabilidad } \\
\text { pública. Los hallazgos demuestran un pensamiento } \\
\text { mayoritariamente avanzado en las dos ciudades } \\
\text { suecas, hay una clara salida de un "predecir y } \\
\text { proporcionar" abordar la comprensión de que la } \\
\text { congestión en la red de carreteras es inevitable y un } \\
\text { énfasis clave en la mejora del transporte público. }\end{array}$ & $\begin{array}{lr}\text { Los diseñadores } & \text { de } \\
\text { políticas en los casos de } \\
\text { Gotemburgo } \\
\text { Estocolmo y } \\
\text { facilitando están, } \\
\text { transición hacia un } \\
\text { sistema de transporte } \\
\text { más sostenible porque } \\
\text { han implementado } \\
\text { cargos por congestión } \\
\text { vehicular del automóvil, } \\
\text { mejorando ra } \\
\text { infraestructura } \\
\text { transporte y las ciclo } \\
\text { vías. }\end{array}$ \\
\hline
\end{tabular}




\section{DATOS DE LA PUBLICACIÓN}

\begin{tabular}{|c|c|c|c|c|}
\hline Autor & Año & Nombre de la Investigación & $\begin{array}{c}\begin{array}{c}\text { Revista donde se ubica la } \\
\text { publicación }\end{array} \\
\end{array}$ & Volumen y número \\
\hline $\begin{array}{l}\text { Calvo Poyo, F., } \\
\text { Navarro } \\
\text { Moreno, J., De } \\
\text { Oña, J. }\end{array}$ & $\begin{array}{l}(202 \\
0)\end{array}$ & $\begin{array}{l}\text { Road investment and traffic safety: An international study. } \\
\text { (Inversión vial y Seguridad de tráfico: un estudio internacional). }\end{array}$ & $\begin{array}{l}\text { https://doi.org/10.3390/SU1216633 } \\
2 \\
\text { Revista: Sustainability } \\
\text { (Switzerland) }\end{array}$ & $\begin{array}{l}\text { vol. } 12 \text {, pp. } 1-15 \text {, núm. } \\
6332 \text {, Agosto, } 2020\end{array}$ \\
\hline
\end{tabular}

\begin{tabular}{|c|c|c|c|c|c|}
\hline \multicolumn{6}{|c|}{ CONTENIDO DE LA PUBLICACIÓN } \\
\hline $\begin{array}{l}\text { Tipo y Diseño de } \\
\text { Investigación }\end{array}$ & $\begin{array}{c}\text { Población y } \\
\text { Muestra }\end{array}$ & Instrumentos & $\begin{array}{l}\text { Aspectos } \\
\text { éticos }\end{array}$ & Resultados & Conclusión \\
\hline $\begin{array}{l}\text { Diseño: } \\
\text { Descriptivo. } \\
\text { Tipo: } \\
\text { comparativo. }\end{array}$ & $\begin{array}{l}\text { Modelo de datos de } \\
23 \text { países europeos } \\
\text { para el período } 1998 \text { - } \\
2016 .\end{array}$ & $\begin{array}{l}\text { Ficha de recojo } \\
\text { de datos. }\end{array}$ & $\begin{array}{l}\text { No conflicto } \\
\text { de interés. }\end{array}$ & $\begin{array}{l}\text { Existe una relación positiva significativa para la } \\
\text { inversión en la construcción de carreteras, y el } \\
\text { gasto en mantenimiento vial, tienen un efecto } \\
\text { sobre la seguridad vial. }\end{array}$ & $\begin{array}{l}\text { El gasto en mantenimiento } \\
\text { y conservación de } \\
\text { carreteras tiene un impacto } \\
\text { positivo en la sociedad, más } \\
\text { allá de prevenir el deterioro } \\
\text { de la infraestructura y } \\
\text { prolongar su vida útil, } \\
\text { contribuye a reducir las } \\
\text { muertes en las carreteras, } \\
\text { aportando el valor agregado } \\
\text { de un sistema de transporte } \\
\text { más seguro y sostenible. }\end{array}$ \\
\hline
\end{tabular}

\section{DATOS DE LA PUBLICACIÓN}




\begin{tabular}{|c|c|c|c|c|}
\hline Autor & Año & Nombre de la Investigación & $\begin{array}{c}\text { Revista donde se ubica la } \\
\text { publicación }\end{array}$ & Volumen y número \\
\hline He, Q., Cao, X. & $\begin{array}{l}(201 \\
9)\end{array}$ & $\begin{array}{l}\text { Pattern and influencing factors of foreign direct investment } \\
\text { networks between countries along the "belt and road" regions. } \\
\text { (Patrón y factores que influyen en las redes de inversión } \\
\text { extranjera directa entre países a lo largo del } \\
\text { Regiones "Belt and Road"). }\end{array}$ & $\begin{array}{l}\text { https://doi.org/10.3390/su1117472 } \\
4 \\
\text { Revista: Sustainability } \\
\text { (Switzerland) }\end{array}$ & $\begin{array}{l}\text { vol. 11, pp. 1-23, núm. } \\
\text { 4724, Setiembre, } 2019\end{array}$ \\
\hline
\end{tabular}

\section{CONTENIDO DE LA PUBLICACIÓN}

\begin{tabular}{|c|c|c|c|c|c|}
\hline $\begin{array}{l}\text { Tipo y Diseño de } \\
\text { Investigación }\end{array}$ & $\begin{array}{c}\text { Población y } \\
\text { Muestra }\end{array}$ & Instrumentos & $\begin{array}{l}\text { Aspectos } \\
\text { éticos }\end{array}$ & Resultados & Conclusión \\
\hline $\begin{array}{l}\text { Diseño: } \\
\text { Descriptivo. } \\
\text { Tipo: } \\
\text { Comparativo. }\end{array}$ & $\begin{array}{l}50 \text { países de } 2003 \text { a } \\
2017 \text { de China y los } \\
\text { países regionales de } \\
\text { la Franja y la Ruta. }\end{array}$ & $\begin{array}{l}\text { Ficha de recojo } \\
\text { de datos. }\end{array}$ & $\begin{array}{l}\text { No conflicto } \\
\text { de interés. }\end{array}$ & $\begin{array}{l}\text { Los países de Europa central y oriental muestran un } \\
\text { comportamiento de agrupación significativo. } \\
\text { Además, la red evolucionó lentamente y siguió la } \\
\text { "regla de Pareto" en las primeras etapas de su } \\
\text { evolución. El BRI fue un punto de inflexión en el } \\
\text { proceso de evolución. Sobre esta base, se utilizó el } \\
\text { método de análisis de regresión del procedimiento de } \\
\text { asignación cuadrática (QAP) para estudiar más a } \\
\text { fondo los factores y realizar el proceso de formación } \\
\text { de este patrón de inversión. }\end{array}$ & $\begin{array}{l}\text { El nivel de desarrollo } \\
\text { económico depende de } \\
\text { la distancia geográfica y } \\
\text { el comercio bilateral red } \\
\text { de inversión regional de } \\
\text { la Franja y la Ruta. }\end{array}$ \\
\hline
\end{tabular}

DATOS DE LA PUBLICACIÓN

Ciencia Latina Revista Científica Multidisciplinar, Ciudad de México, México. ISN 2707-2207 / ISSN 2707-2215 (en línea), julio-agosto, 2021, Volumen 5, Número 4. https://doi.org/10.37811/cl_rcm.v5i4.772 p.6308 


\begin{tabular}{|c|c|c|c|c|}
\hline Autor & Año & Nombre de la Investigación & $\begin{array}{l}\text { Revista donde se ubica la } \\
\text { publicación }\end{array}$ & Volumen y número \\
\hline $\begin{array}{l}\text { Sihombing, L. } \\
\text { B., Latief, Y., } \\
\text { Rarasati, A.D., } \\
\text { Wibowo, A. }\end{array}$ & $\begin{array}{l}(201 \\
8)\end{array}$ & $\begin{array}{l}\text { Project financing models for toll road investments: A state of the } \\
\text { art literature review. } \\
\text { (Modelos de financiamiento de proyectos para inversiones en } \\
\text { carreteras de peaje: Una revisión de la literatura de vanguardia) }\end{array}$ & $\begin{array}{l}\text { https://doi.org/10.13189/cea.2018.0 } \\
60301 \\
\text { Revista: Civil Engineering and } \\
\text { Architecture }\end{array}$ & $\begin{array}{l}\text { vol. } 6 \text {, pp.115-127, } \\
\text { Mayo, } 2018\end{array}$ \\
\hline
\end{tabular}

\section{CONTENIDO DE LA PUBLICACIÓN}

\begin{tabular}{|c|c|c|c|c|c|}
\hline $\begin{array}{l}\text { Tipo y Diseño de } \\
\text { Investigación }\end{array}$ & $\begin{array}{l}\text { Población y } \\
\text { Muestra }\end{array}$ & Instrumentos & $\begin{array}{l}\text { Aspectos } \\
\text { éticos }\end{array}$ & Resultados & Conclusión \\
\hline $\begin{array}{l}\text { Diseño: } \\
\text { Descriptivo, } \\
\text { cualitativo y } \\
\text { cuantitativo. } \\
\text { Tipo: } \\
\text { Comparativo. }\end{array}$ & $\begin{array}{l}29 \text { artículos de } \\
\text { concesiones de } \\
\text { carreteras en } 18 \text { años } \\
\text { (1999-2017). } \\
\text { EE. UU., India, } \\
\text { China, Japón e } \\
\text { Indonesia. }\end{array}$ & $\begin{array}{l}\text { Guía de análisis } \\
\text { de datos. }\end{array}$ & No refiere. & $\begin{array}{l}\text { Se han identificado tres problemas como fuentes } \\
\text { potenciales de esta insostenibilidad, como la } \\
\text { incertidumbre de los ingresos del proyecto a largo plazo, } \\
\text { las restricciones presupuestarias proporcionadas por el } \\
\text { gobierno y el apoyo gubernamental inadecuado para la } \\
\text { adquisición de tierras donde se construirán las } \\
\text { infraestructuras viales. Las segundas carreteras más } \\
\text { largas del mundo se encuentran en China, con } 45.000 \mathrm{~km} \text {. }\end{array}$ & $\begin{array}{l}\text { Los modelos de } \\
\text { financiación de } \\
\text { proyectos viales son } \\
\text { en mayoría } \\
\text { construidas con la } \\
\text { inversión pública } \\
\text { (impuestos, } \\
\text { contribuciones, } \\
\text { aportaciones, } \\
\text { concesiones). }\end{array}$ \\
\hline
\end{tabular}

\section{DATOS DE LA PUBLICACIÓN}




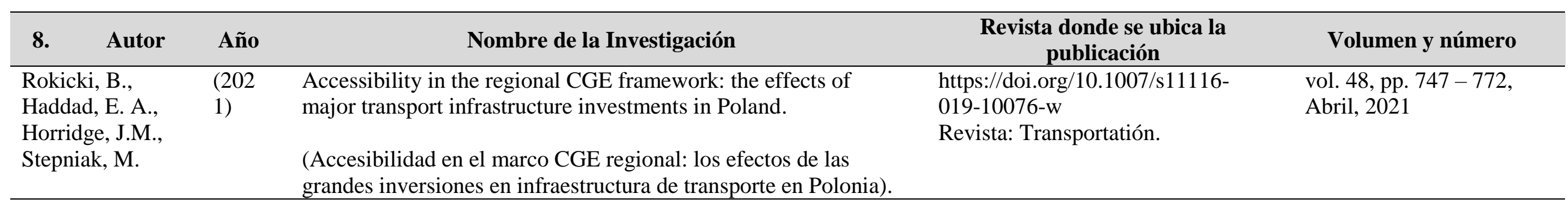

\section{CONTENIDO DE LA PUBLICACIÓN}

\begin{tabular}{|c|c|c|c|c|c|}
\hline $\begin{array}{l}\text { Tipo y Diseño de } \\
\text { Investigación }\end{array}$ & $\begin{array}{c}\text { Población y } \\
\text { Muestra }\end{array}$ & Instrumentos & $\begin{array}{l}\text { Aspectos } \\
\text { éticos }\end{array}$ & Resultados & Conclusión \\
\hline $\begin{array}{l}\text { Diseño: } \\
\text { Descriptivo, } \\
\text { cualitativo y } \\
\text { cuantitativo. } \\
\text { Tipo: } \\
\text { Comparativo. }\end{array}$ & $\begin{array}{l}\text { Modelo de } 16 \\
\text { regiones NUTS } 2 \text { y } \\
55 \text { industrias Polacas } \\
\text { entre 2005-2015. }\end{array}$ & Entrevistas. & No refiere. & $\begin{array}{l}\text { El modelo dinámico regional sirve para medir los } \\
\text { efectos de las grandes inversiones en } \\
\text { infraestructura de transporte en las regiones } \\
\text { polacas, utiliza datos tanto sobre el gasto en } \\
\text { inversión como sobre la mejora de la accesibilidad } \\
\text { (expresada como una reducción en los márgenes de } \\
\text { transporte), para distinguir entre posibles impactos } \\
\text { a corto y largo plazo. }\end{array}$ & $\begin{array}{l}\text { Las regiones polacas } \\
\text { tienen principales } \\
\text { inversiones } \\
\text { infraestructura de } \\
\text { carreteras por inversores } \\
\text { privados y públicos. En el } \\
\text { caso del primero, la falta } \\
\text { de inversión conduciría a } \\
\text { una disminución } \\
\text { relativamente } \\
\text { significativa del producto } \\
\text { bruto interno PIB real o } \\
\text { del empleo promedio. En } \\
\text { el caso del segundo, el } \\
\text { impacto de las grandes } \\
\text { inversiones } \\
\text { infraestructura vial es casi } \\
\text { insignificante. }\end{array}$ \\
\hline
\end{tabular}

\section{DATOS DE LA PUBLICACIÓN}




\begin{tabular}{|c|c|c|c|c|}
\hline Autor & Año & Nombre de la Investigación & $\begin{array}{c}\text { Revista donde se ubica la } \\
\text { publicación }\end{array}$ & Volumen y número \\
\hline $\begin{array}{l}\text { Latif, M. A., } \\
\text { Chazali, Z. A. }\end{array}$ & $\begin{array}{l}\text { (201 } \\
9)\end{array}$ & $\begin{array}{l}\text { Value management / value engineering (VM/VE) applicatión in } \\
\text { Malaysian public construction projects: Application of VM/VE } \\
\text { study improved roads project sustainability. } \\
\text { (Aplicación de gestión de valor / ingeniería de valor (VM / VE) } \\
\text { en proyectos de construcción pública de Malasia: aplicación del } \\
\text { estudio VM / VE mejoró la sostenibilidad del proyecto de } \\
\text { carreteras). }\end{array}$ & $\begin{array}{l}\text { https://doi.org/10.1088/1757- } \\
\text { 899X/512/1/012046 } \\
\text { Revista: IOP Conference Series: } \\
\text { Materials Science and Engineering. }\end{array}$ & $\begin{array}{l}\text { vol. 512, pp. } 1-12 \text {, } \\
\text { núm. 012046, Abril, } \\
2019\end{array}$ \\
\hline
\end{tabular}

\begin{tabular}{|c|c|c|c|c|c|}
\hline \multicolumn{6}{|c|}{ CONTENIDO DE LA PUBLICACIÓN } \\
\hline $\begin{array}{l}\text { Tipo y Diseño de } \\
\text { Investigación }\end{array}$ & $\begin{array}{l}\text { Población y } \\
\text { Muestra }\end{array}$ & Instrumentos & $\begin{array}{c}\text { Aspectos } \\
\text { éticos }\end{array}$ & Resultados & Conclusión \\
\hline $\begin{array}{l}\text { Diseño: } \\
\text { Descriptivo. } \\
\text { Tipo: } \\
\text { Comparativo. }\end{array}$ & $\begin{array}{l}\text { Seis (6) estudios de } \\
\text { caso de VE para } \\
\text { infraestructuras } \\
\text { viales de Malasia. }\end{array}$ & $\begin{array}{l}\text { Ficha de recojo } \\
\text { de datos. }\end{array}$ & $\begin{array}{l}\text { No conflicto } \\
\text { de interés. }\end{array}$ & $\begin{array}{l}\text { La aplicación de gestión de valor / ingeniería de valor } \\
\text { (VM / VE). Se establece una relación entre la } \\
\text { metodología / proceso VM / VE con el concepto de } \\
\text { sustentabilidad, lo que permite potenciar y alcanzar los } \\
\text { valores previstos del proyecto. }\end{array}$ & $\begin{array}{lr}\text { El enfoque en } \\
\text { Malasia muestra } \\
\text { un impacto } \\
\text { significativo en la } \\
\text { mejora de la } \\
\text { sostenibilidad en } \\
\text { proyectos viales } \\
\text { apoyados ron } \\
\text { herramientas } \\
\text { técnicas de gestión } \\
\text { de valor. } \\
\end{array}$ \\
\hline
\end{tabular}

\section{DATOS DE LA PUBLICACIÓN}




\begin{tabular}{|c|c|c|c|c|}
\hline 10. Autor & Año & Nombre de la Investigación & $\begin{array}{c}\text { Revista donde se ubica la } \\
\text { publicación }\end{array}$ & Volumen y número \\
\hline $\begin{array}{l}\text { Rust, F. C., } \\
\text { Sampson, R. }\end{array}$ & $\begin{array}{l}(202 \\
0)\end{array}$ & $\begin{array}{l}\text { A systems-based R\&D management model for the road and } \\
\text { transport engineering sector applied to a community access } \\
\text { roads and transport research programme. } \\
\text { (Un modelo de gestión de I + D basado en sistemas para el } \\
\text { sector de la ingeniería de carreteras y transporte aplicado a un } \\
\text { programa de investigación de carreteras de acceso comunitario y } \\
\text { transporte). }\end{array}$ & $\begin{array}{l}\text { https://doi.org/10.1080/20421338.2 } \\
019.1640344 \\
\text { Revista: African Journal of } \\
\text { Science, Technology, Innovatión } \\
\text { and Development. }\end{array}$ & $\begin{array}{l}\text { vol.12, pp. } 547-560 \text {, } \\
\text { Julio, } 2020\end{array}$ \\
\hline
\end{tabular}

\begin{tabular}{|c|c|c|c|c|c|}
\hline \multicolumn{6}{|c|}{ CONTENIDO DE LA PUBLICACIÓN } \\
\hline $\begin{array}{l}\text { Tipo y Diseño de } \\
\text { Investigación }\end{array}$ & $\begin{array}{l}\text { Población y } \\
\text { Muestra }\end{array}$ & Instrumentos & $\begin{array}{c}\text { Aspectos } \\
\text { éticos }\end{array}$ & Resultados & Conclusión \\
\hline $\begin{array}{l}\text { Diseño: } \\
\text { Aplicado. } \\
\text { Tipo: } \\
\text { Comparativo. }\end{array}$ & $\begin{array}{l}126 \text { organizaciones } \\
\text { sudafricanas e } \\
\text { internacionales, entre } \\
\text { ellos los } \\
\text { sectores de } \\
\text { transporte, } \\
\text { infraestructura, } \\
\text { ingeniería vial y } \\
\text { construcción. }\end{array}$ & $\begin{array}{l}\text { Entrevistas y } \\
\text { encuesta. }\end{array}$ & No refiere. & $\begin{array}{l}\text { El modelo conceptual no lineal de gestión de I + D } \\
\text { basado en sistemas para el sector de las carreteras y el } \\
\text { transporte aborda las complejidades asociadas sobre el } \\
\text { transporte y las carreteras con un enfoque de proceso, } \\
\text { tanto el pensamiento "hacia atrás" (retroceso) como el } \\
\text { "hacia adelante", facilita así el impacto y la aceptación } \\
\text { eventuales. Incluye un "sensor" de evaluación de } \\
\text { impacto en el proceso de I + D. Se aumentó los } \\
\text { indicadores clave de rendimiento en un transporte. }\end{array}$ & $\begin{array}{l}\text { Un enfoque basado } \\
\text { en procesos puede } \\
\text { mejorar ros } \\
\text { indicadores de } \\
\text { evaluación de de } \\
\text { impacto de un } \\
\text { programa de I + D, } \\
\text { de investigación de } \\
\text { carreteras de acceso }\end{array}$ \\
\hline & & & & & $\begin{array}{lr}\text { comunitario } & \text { y } \\
\text { transporte } & \text { en } \\
\text { África. } & \end{array}$ \\
\hline
\end{tabular}

\section{DATOS DE LA PUBLICACIÓN}

Ciencia Latina Revista Científica Multidisciplinar, Ciudad de México, México. ISN 2707-2207 / ISSN 2707-2215 (en línea), julio-agosto, 2021, Volumen 5, Número 4. https://doi.org/10.37811/cl_rcm.v5i4.772 p.6312 


\begin{tabular}{|c|c|c|c|c|}
\hline Autor & Año & Nombre de la Investigación & $\begin{array}{c}\text { Revista donde se ubica la } \\
\text { publicación }\end{array}$ & Volumen y número \\
\hline $\begin{array}{l}\text { Slavinska, O., } \\
\text { Stozhka, V., } \\
\text { Kharchenko, A., } \\
\text { Bubela, A., } \\
\text { Kvatadze, A. }\end{array}$ & $\begin{array}{l}\text { (201 } \\
9)\end{array}$ & $\begin{array}{l}\text { Development of a model of the weight of motor roads parameters } \\
\text { as part of the information and management system of monetary } \\
\text { evaluation. } \\
\text { (Desarrollo de un modelo del peso de carreteras de motor } \\
\text { parámetros como parte de la información y gestión sistema de } \\
\text { monetario evaluación). }\end{array}$ & $\begin{array}{l}\text { https://doi.org/10.15587/1729- } \\
\text { 4061.2019.156519 } \\
\text { Revista: Eastern European Journal } \\
\text { of Enterprise Technologies. }\end{array}$ & Vol.1, pp. $46-59,2019$ \\
\hline
\end{tabular}

\section{CONTENIDO DE LA PUBLICACIÓN}

\begin{tabular}{|c|c|c|c|c|c|}
\hline $\begin{array}{l}\text { Tipo y Diseño de } \\
\text { Investigación }\end{array}$ & $\begin{array}{c}\text { Población y } \\
\text { Muestra }\end{array}$ & Instrumentos & $\begin{array}{l}\text { Aspectos } \\
\text { éticos }\end{array}$ & Resultados & Conclusión \\
\hline $\begin{array}{l}\text { Diseño: } \\
\text { Descriptivo } \\
\text { Tipo: } \\
\text { Comparativo }\end{array}$ & $\begin{array}{l}\text { Modelo casos de } \\
\text { infraestructura vial } \\
\text { de la autopista del } \\
\text { gobierno de Ucrania. }\end{array}$ & $\begin{array}{l}\text { Ficha de recojo } \\
\text { de datos }\end{array}$ & No refiere. & $\begin{array}{l}\text { El modelo permite estimar el estado de calidad de un } \\
\text { objeto por su desgaste físico y funcional. La adecuación } \\
\text { del modelo propuesto se demuestra por el error estándar } \\
\text { del } 5 \% \text { y la significancia de la relación por el criterio F } \\
\text { de Fisher, que se estableció con probabilidad de } 0,95 \text { y } \\
\text { demuestra la confiabilidad del modelo desarrollado de la } \\
\text { red existente de vías públicas. }\end{array}$ & \begin{tabular}{lr}
\multicolumn{3}{l}{ La gestión eficiente } \\
de la red existente \\
de vías públicas de \\
Ucrania \\
importancia \\
nacional y deben ser \\
prioritarios \\
mejorar para \\
propiedades & las \\
consumo de & los \\
corredores & de \\
transporte & \\
internacionales & y \\
nacionales. &
\end{tabular} \\
\hline
\end{tabular}

\section{DATOS DE LA PUBLICACIÓN}




\begin{tabular}{lllll}
\hline 12. Autor & Año & \multicolumn{1}{c}{ Nombre de la Investigación } & \multicolumn{1}{c}{$\begin{array}{c}\text { Revista donde se ubica la } \\
\text { publicación }\end{array}$} & \multicolumn{1}{c}{ Volumen y número } \\
\hline Cortés, R. & $(201$ & ¿Qué tan competitivos son los países miembros de la Alianza del & https://doi.org/10.21158/01208160. & núm. 85, pp.143 - 162, \\
& 8) & Pacífico en infraestructura de transporte? & Revista: EAN & Julio - Diciembre, 2018 \\
& & & & \\
\hline
\end{tabular}

\section{CONTENIDO DE LA PUBLICACIÓN}

\begin{tabular}{|c|c|c|c|c|c|}
\hline $\begin{array}{l}\text { Tipo y Diseño de } \\
\text { Investigación }\end{array}$ & $\begin{array}{c}\text { Población y } \\
\text { Muestra }\end{array}$ & Instrumentos & $\begin{array}{l}\text { Aspectos } \\
\text { éticos }\end{array}$ & Resultados & Conclusión \\
\hline $\begin{array}{l}\text { Diseño: } \\
\text { Descriptivo. } \\
\text { Tipo: } \\
\text { comparativo. }\end{array}$ & $\begin{array}{l}\text { Modelo casos de } \\
\text { Banco Mundial, } \\
\text { World Economic } \\
\text { Forum (WEF), } \\
\text { Economic } \\
\text { Commission for } \\
\text { Latin America and } \\
\text { the Caribbean } \\
\text { (ECLAC) } \\
\text { Infralatam, del } \\
\text { periodo 2006-2016 }\end{array}$ & $\begin{array}{l}\text { Ficha de recojo } \\
\text { de datos. }\end{array}$ & No refiere. & $\begin{array}{l}\text { La inversión en la red vial tiene dimensiones que calculan } \\
\text { los resultados de la competitividad, como los gastos, } \\
\text { periodo, excelencia y rendimiento operativo. }\end{array}$ & $\begin{array}{l}\text { La calidad de la } \\
\text { infraestructura vial } \\
\text { de los países de la } \\
\text { Alianza } \\
\text { Pacifico son su } \\
\text { principal objetivo. }\end{array}$ \\
\hline
\end{tabular}

\subsection{Tablas de estudios revisados de Procesos de Gestión.}

Ciencia Latina Revista Científica Multidisciplinar, Ciudad de México, México. ISN 2707-2207 / ISSN 2707-2215 (en línea), julio-agosto, 2021, Volumen 5, Número 4. https://doi.org/10.37811/cl_rcm.v5i4.772 p.6314 


\section{DATOS DE LA PUBLICACIÓN}

\begin{tabular}{|c|c|c|c|c|}
\hline Autor & Año & Nombre de la Investigación & $\begin{array}{c}\text { Revista donde se ubica la } \\
\text { publicación }\end{array}$ & Volumen y número \\
\hline $\begin{array}{l}\text { Medina León, Alberto., } \\
\text { Nogueira Rivera, } \\
\text { Dianelys., } \\
\text { Hernández Nariño, } \\
\text { Arialys., Comas } \\
\text { Rodríguez, Raúl. }\end{array}$ & (2019) & $\begin{array}{l}\text { Procedimiento para la gestión por procesos: métodos y } \\
\text { herramientas de apoyo. }\end{array}$ & $\begin{array}{l}\text { https://doi.org/10.4067/S0718- } \\
\text { 33052019000200328 } \\
\text { Revista: Ingeniare. chilena de } \\
\text { ingeniería. }\end{array}$ & $\begin{array}{l}\text { vol.27, núm. 2, pp. } 328 \\
\text { - 342, abril, } 2019\end{array}$ \\
\hline
\end{tabular}

\section{CONTENIDO DE LA PUBLICACIÓN}

\begin{tabular}{|c|c|c|c|c|c|}
\hline $\begin{array}{l}\text { Tipo y Diseño de } \\
\text { Investigación }\end{array}$ & $\begin{array}{l}\text { Población y } \\
\text { Muestra }\end{array}$ & Instrumentos & $\begin{array}{l}\text { Aspectos } \\
\text { éticos }\end{array}$ & Resultados & Conclusión \\
\hline $\begin{array}{l}\text { Diseño: } \\
\text { Descriptivo. } \\
\text { Tipo: Comparativo. }\end{array}$ & $\begin{array}{l}80 \text { modelos } \text { de } \\
\text { casos } \quad \text { su } \\
\text { aplicación } \\
\text { parcial por más } \\
\text { de } 10 \text { años en, al } \\
\text { menos, } \quad 40 \\
\text { empresas de } \\
\text { manufactura. }\end{array}$ & $\begin{array}{l}\text { Ficha de } \\
\text { procesos. }\end{array}$ & No refiere & $\begin{array}{l}\text { La Mejora de Procesos se basa en un esfuerzo grupal } \\
\text { donde se incluya a expertos con competencias, } \\
\text { habilidades gerenciales y poder de decisión. Se examinó } \\
\text { con enfoques de calidad y seguridad ambiental. La meta } \\
\text { se centra en su facultad de decidir primero en los } \\
\text { procesos de mayor impacto organizacional y en el } \\
\text { cumplimento de los objetivos estratégicos de un buena } \\
\text { atención al ciudadano. }\end{array}$ & $\begin{array}{l}\text { El valor } \\
\text { científico, } \\
\text { direcciona a los } \\
\text { miembros del } \\
\text { equipo a la mejora } \\
\text { continua de los } \\
\text { procesos } \\
\text { primordiales } \\
\text { líderes de la } \\
\text { organización, } \\
\text { como un óptimo } \\
\text { uso del tiempo. }\end{array}$ \\
\hline
\end{tabular}

\section{DATOS DE LA PUBLICACIÓN}




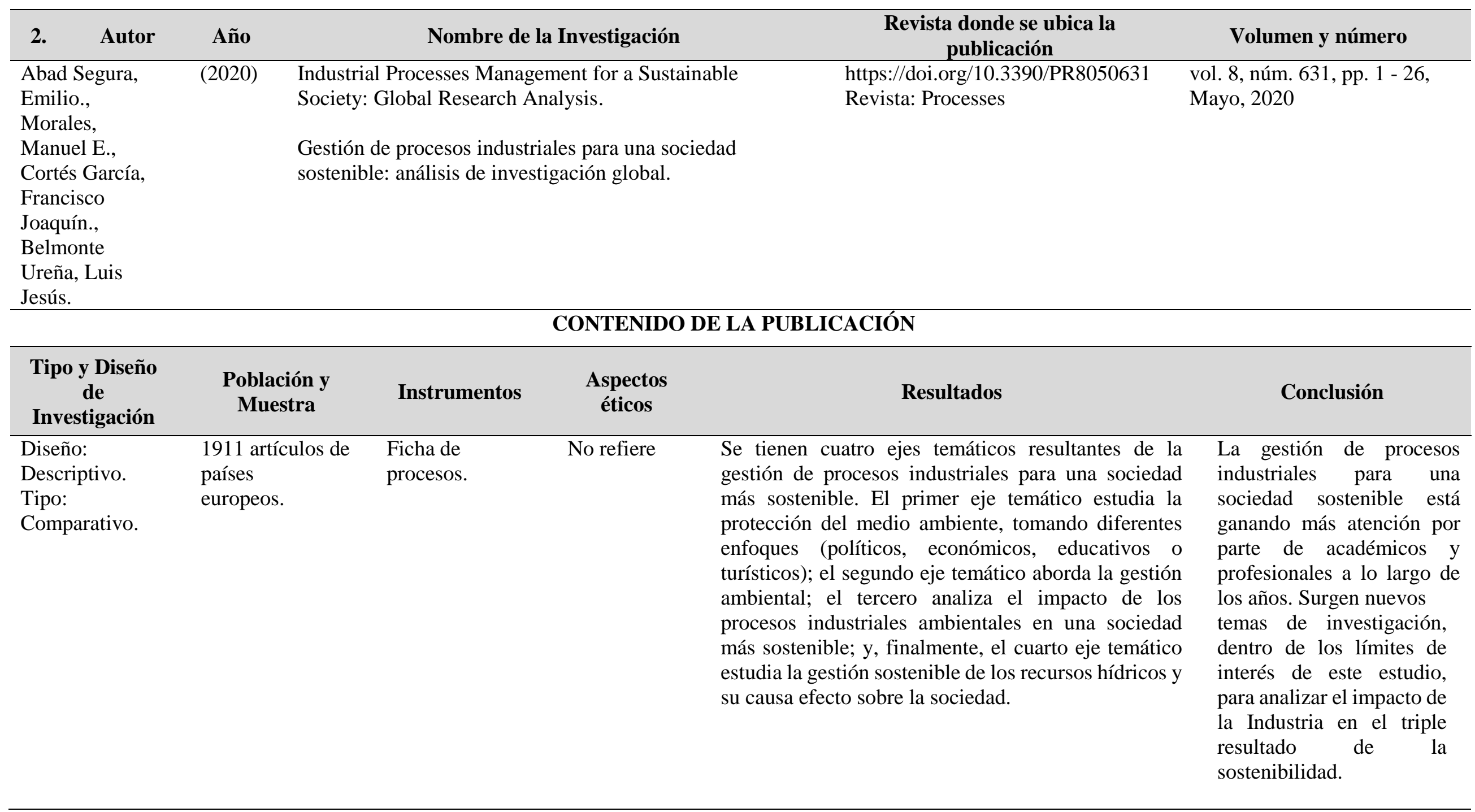




\section{DATOS DE LA PUBLICACIÓN}

\begin{tabular}{|c|c|c|c|c|}
\hline Autor & Año & Nombre de la Investigación & $\begin{array}{l}\text { Revista donde se ubica la } \\
\text { publicación }\end{array}$ & Volumen y número \\
\hline $\begin{array}{l}\text { Waris, Muhammad., } \\
\text { Panigrahi, Shrikant., } \\
\text { Mengal, Abdullah., } \\
\text { Soomro, Mujeeb } \\
\text { Iqbal., Mirjat, Nayyar } \\
\text { Hussain., Ullah, } \\
\text { Mehfooz., Azlan, } \\
\text { Zarith Sufia., Khan, } \\
\text { Asadullah. }\end{array}$ & (2019) & $\begin{array}{l}\text { An application of analytic hierarchy process (ahp) for } \\
\text { sustainable procurement of construction equipment: } \\
\text { Multicriteria based decisión framework for Malaysia. } \\
\text { Una aplicación del proceso de jerarquía analítica (AHP) } \\
\text { para la adquisición sostenible de equipos de construcción: } \\
\text { marco de decisiones basado en criterios múltiples para } \\
\text { Malasia. }\end{array}$ & $\begin{array}{l}\text { https://doi.org/10.1155 / } \\
\text { 2019/6391431 } \\
\text { Revista: Mathematical Problems in } \\
\text { Engineering }\end{array}$ & $\begin{array}{l}\text { Vol. 2019, núm. } \\
6391431 \text {, pp. } 1 \text { - } 20 \\
\text {,2019 }\end{array}$ \\
\hline
\end{tabular}

\section{CONTENIDO DE LA PUBLICACIÓN}

\begin{tabular}{|c|c|c|c|c|c|}
\hline $\begin{array}{c}\text { Tipo y Diseño de } \\
\text { Investigación }\end{array}$ & $\begin{array}{c}\text { Población y } \\
\text { Muestra }\end{array}$ & Instrumentos & $\begin{array}{c}\text { Aspectos } \\
\text { éticos }\end{array}$ & Resultados & Conclusión \\
\hline $\begin{array}{l}\text { Diseño: } \\
\text { Cualitativo y } \\
\text { cuantitativo Tipo: } \\
\text { Comparativo. }\end{array}$ & $\begin{array}{l}\text { Modelo de caso } \\
\text { del gobierno de } \\
\text { Malasia. }\end{array}$ & Encuesta. & $\begin{array}{l}\text { No } \\
\text { conflicto } \\
\text { de interés. }\end{array}$ & $\begin{array}{l}\text { El índice de procesos de adquisiciones sostenibles para } \\
\text { las empresas constructoras de Malasia. Entre ellos, se } \\
\text { encuentra que el costo del ciclo de vida es un factor de } \\
\text { decisión importante en la selección de equipos de } \\
\text { movimiento de tierras sostenibles y tiene un peso } \\
\text { porcentual del } 38,5 \% \text {. También tiene el valor más alto } \\
\text { de vector de prioridad, lo que representa que los } \\
\text { tomadores de decisiones lo han considerado } \\
\text { significativamente más importante. Le siguen otros } \\
\text { criterios principales, es decir, actuación (17,6\%), } \\
\text { capacidad del sistema16,5\%), y conveniencia operativa } \\
\text { (12,8\%), tienen mayores valores de importancia e } \\
\text { indexa ponderaciones para impacto medioambiental. } \\
\text { Las adquisiciones sostenibles es uno de los beneficios }\end{array}$ & $\begin{array}{l}\text { Los procesos en la } \\
\text { industria de la } \\
\text { construcción de Malasia se } \\
\text { inclinan hacia la selección } \\
\text { de materiales, sostenibles, } \\
\text { existe una brecha entre la } \\
\text { evaluación del enfoque de } \\
\text { selección de equipos y la } \\
\text { inclusión del concepto de } \\
\text { sustentabilidad en la } \\
\text { aprobación durante la fase } \\
\text { de adquisición de un } \\
\text { proyecto. }\end{array}$ \\
\hline
\end{tabular}




\section{DATOS DE LA PUBLICACIÓN}

\begin{tabular}{|c|c|c|c|c|}
\hline Autor & Año & Nombre de la Investigación & $\begin{array}{c}\begin{array}{c}\text { Revista donde se ubica la } \\
\text { publicación }\end{array} \\
\end{array}$ & Volumen y número \\
\hline \multirow[t]{3}{*}{$\begin{array}{l}\text { Njenga, Peter., } \\
\text { Tanzarn. Nite. }\end{array}$} & $(2020)$ & $\begin{array}{l}\text { Scaling up gender mainstreaming in transport: Policies, } \\
\text { practices and monitoring processes. }\end{array}$ & $\begin{array}{l}\text { https://doi.org/10.1680/jtran.18.001 } \\
52\end{array}$ & $\begin{array}{l}\text { Vol. } 173 \text {, pp. } 64-75 \text {, Abril, } \\
2020\end{array}$ \\
\hline & & & Revista: Proceedings of the & \\
\hline & & $\begin{array}{l}\text { Ampliación de la integración de la perspectiva de } \\
\text { género en el transporte: políticas, prácticas y } \\
\text { procesos de seguimiento. }\end{array}$ & $\begin{array}{l}\text { Institution of Civil Engineers: } \\
\text { Transport }\end{array}$ & \\
\hline
\end{tabular}

\section{CONTENIDO DE LA PUBLICACIÓN}

\begin{tabular}{|c|c|c|c|c|c|}
\hline $\begin{array}{l}\text { Tipo y Diseño de } \\
\text { Investigación }\end{array}$ & $\begin{array}{c}\text { Población y } \\
\text { Muestra }\end{array}$ & Instrumentos & $\begin{array}{c}\text { Aspectos } \\
\text { éticos }\end{array}$ & Resultados & Conclusión \\
\hline $\begin{array}{l}\text { Diseño: } \\
\text { Descriptivo. } \\
\text { Tipo: } \\
\text { Comparativo. }\end{array}$ & $\begin{array}{l}\text { Modelo de } 4 \\
\text { casos del } \\
\text { programa de } \\
\text { transporte rural } \\
\text { de Ghana, } \\
\text { Uganda, Kenia y } \\
\text { Tanzania }\end{array}$ & Entrevista & No refiere & $\begin{array}{l}\text { Nunca puede haber desarrollo sostenible si se exonera la } \\
\text { participación de la mujer en los procesos y, resultados de } \\
\text { los programas de inversión. El transporte es un factor } \\
\text { clave para el logro de mayores objetivos en los países en } \\
\text { desarrollo (pobreza, salud, educación, agua potable, } \\
\text { energía, etc.). En todos los proyectos han incorporado el } \\
\text { género (mujeres) en todas las etapas del ciclo del } \\
\text { proyecto. }\end{array}$ & $\begin{array}{l}\text { Se han logrado buenos } \\
\text { avances en la } \\
\text { incorporación de la } \\
\text { igualdad de género en } \\
\text { las leyes y en la política } \\
\text { del sector transporte de } \\
\text { los cuatro programas } \\
\text { nacionales de } \\
\text { transporte que son el } \\
\text { tema de esta } \\
\text { investigación. }\end{array}$ \\
\hline
\end{tabular}




\section{DATOS DE LA PUBLICACIÓN}

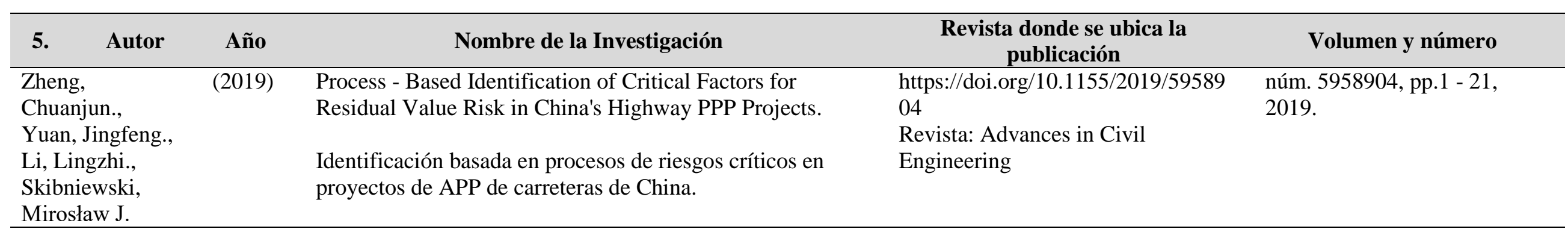

\section{CONTENIDO DE LA PUBLICACIÓN}

\begin{tabular}{|c|c|c|c|c|c|}
\hline $\begin{array}{l}\text { Tipo y Diseño de } \\
\text { Investigación }\end{array}$ & $\begin{array}{c}\text { Población y } \\
\text { Muestra }\end{array}$ & Instrumentos & $\begin{array}{l}\text { Aspectos } \\
\text { éticos }\end{array}$ & Resultados & Conclusión \\
\hline $\begin{array}{l}\text { Diseño: } \\
\text { Descriptivo. } \\
\text { Tipo: } \\
\text { Comparativo. }\end{array}$ & $\begin{array}{l}\text { Modelo de } 98 \\
\text { casos de } \\
\text { proyectos de } \\
\text { carreteras de } \\
\text { China }\end{array}$ & Encuesta & $\begin{array}{l}\text { No conflicto } \\
\text { de interés. }\end{array}$ & $\begin{array}{l}\text { Los gobiernos de todo el mundo han adoptado cada vez } \\
\text { más las asociaciones público-privadas (APP) para } \\
\text { ofrecer infraestructura y servicios públicos a gran escala, } \\
\text { especialmente en la provisión de infraestructura de } \\
\text { transporte. El modelo validado de la identificación de } \\
\text { procesos de riesgos críticos es la base para evaluar los } \\
\text { proyectos de las carreteras durante los procesos del } \\
\text { proyecto. La gestión del ciclo de vida y las asociaciones } \\
\text { a largo plazo que se mantienen entre el sector público y } \\
\text { privado son beneficiosas para la infraestructura vial. }\end{array}$ & $\begin{array}{l}\text { Los procesos de riesgos } \\
\text { críticos en proyectos de } \\
\text { carreteras contribuyen } \\
\text { al desarrollo y la } \\
\text { sostenibilidad de los } \\
\text { proyectos de las } \\
\text { carreteras en China. }\end{array}$ \\
\hline
\end{tabular}




\section{DATOS DE LA PUBLICACIÓN}

\begin{tabular}{|c|c|c|c|c|}
\hline 6. Autor & Año & Nombre de la Investigación & $\begin{array}{c}\text { Revista donde se ubica la } \\
\text { publicación }\end{array}$ & Volumen y número \\
\hline \multirow[t]{2}{*}{$\begin{array}{l}\text { Sánchez Rubio, } \\
\text { Juan Luis. }\end{array}$} & $(2021)$ & $\begin{array}{l}\text { Model to Optimize the Decision Making on Processes in } \\
\text { IT Departments. }\end{array}$ & $\begin{array}{l}\text { https://doi.org/10.3390/math90909 } \\
\text { 83. } \\
\text { Revista: Mathematics }\end{array}$ & $\begin{array}{l}\text { vol. 9, núm. 983, pp.1 - 23, } \\
\text { Mayo, } 2021\end{array}$ \\
\hline & & $\begin{array}{l}\text { Modelo para optimizar la toma de decisiones sobre } \\
\text { procesos en departamentos de TI. }\end{array}$ & & \\
\hline
\end{tabular}

\section{CONTENIDO DE LA PUBLICACIÓN}

\begin{tabular}{|c|c|c|c|c|c|}
\hline $\begin{array}{l}\text { Tipo y Diseño de } \\
\text { Investigación }\end{array}$ & $\begin{array}{c}\text { Población y } \\
\text { Muestra }\end{array}$ & Instrumentos & $\begin{array}{c}\text { Aspectos } \\
\text { éticos }\end{array}$ & Resultados & Conclusión \\
\hline $\begin{array}{l}\text { Diseño: } \\
\text { Descriptivo. } \\
\text { Tipo: } \\
\text { Comparativo. }\end{array}$ & $\begin{array}{l}\text { Modelo de } \\
\text { pequeñas } \\
\text { empresas de } \\
\text { tecnologías de la } \\
\text { información de } \\
\text { España }\end{array}$ & Encuesta web & $\begin{array}{l}\text { No conflicto } \\
\text { de interés. }\end{array}$ & $\begin{array}{l}\text { El modelo matemático es la base de un algoritmo } \\
\text { codicioso iterativo que genera la secuencia óptima de } \\
\text { procesos en los departamentos de Infraestructura de } \\
\text { Tecnologías de la Información (ITIL) que deben } \\
\text { seguirse en los departamentos de tecnología para su } \\
\text { adecuada gestión a implementar. El algoritmo ha sido } \\
\text { probado en una empresa con resultados satisfactorios: la } \\
\text { secuencia de implementación propuesta permitió a la } \\
\text { empresa gestionar adecuadamente el departamento de } \\
\text { Tecnología de la investigación así como acercarse a la } \\
\text { competencia en base a los objetivos y restricciones } \\
\text { reportados por la empresa. }\end{array}$ & $\begin{array}{l}\text { Lo procesos para } \\
\text { mejorar la gestión } \\
\text { usando modelos } \\
\text { matemáticos es un punto } \\
\text { clave, ya que cada vez } \\
\text { más empresas dependen } \\
\text { de la tecnología. Una } \\
\text { adecuada gestión del } \\
\text { departamento de TI se } \\
\text { apoya en mejores } \\
\text { experiencias para los } \\
\text { usuarios (internos y } \\
\text { externos), y aumenta la } \\
\text { satisfacción y los } \\
\text { ingresos de la empresa. }\end{array}$ \\
\hline
\end{tabular}




\section{DATOS DE LA PUBLICACIÓN}

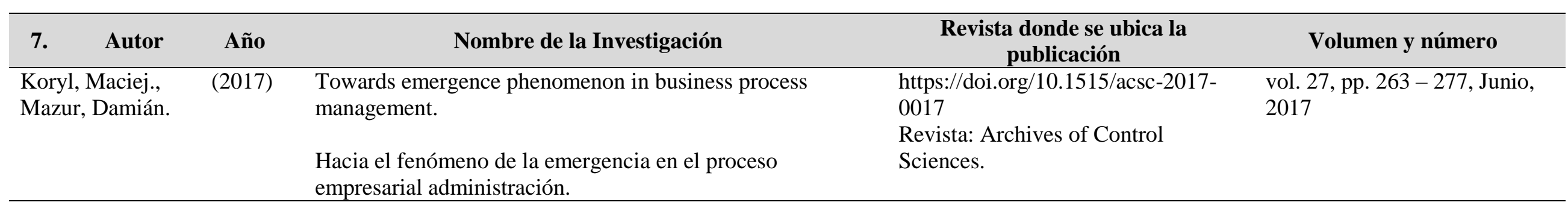

\section{CONTENIDO DE LA PUBLICACIÓN}

\begin{tabular}{|c|c|c|c|c|c|}
\hline $\begin{array}{l}\text { Tipo y Diseño de } \\
\text { Investigación }\end{array}$ & $\begin{array}{l}\text { Población y } \\
\text { Muestra }\end{array}$ & Instrumentos & $\begin{array}{l}\text { Aspectos } \\
\text { éticos }\end{array}$ & Resultados & Conclusión \\
\hline $\begin{array}{l}\text { Diseño: } \\
\text { Descriptivo. } \\
\text { Tipo: } \\
\text { Comparativo. }\end{array}$ & $\begin{array}{l}\text { Modelo de } \\
\text { trabajadores } \\
\text { bancarios, } \\
\text { clientes }\end{array}$ & $\begin{array}{l}\text { Guía de análisis } \\
\text { de datos. }\end{array}$ & No refiere. & $\begin{array}{l}\text { El modelo de diseño de gestión de procesos modernos, } \\
\text { para los trabajadores bancarios se utilizó un software } \\
\text { BRMS (Sistema de gestión de reglas comerciales), } \\
\text { generalmente admite la descripción de la lógica de los } \\
\text { nodos de decisión donde el resultado depende del estado } \\
\text { del caso de negocio que se está procesando y, a veces, } \\
\text { depende del estado del entorno externo. El sistema } \\
\text { descrito utiliza el motor BRMS para almacenar y } \\
\text { ejecutar la lógica de decisión tomada por los actores. }\end{array}$ & $\begin{array}{l}\text { El Motor de gestión de } \\
\text { procesos de negocio del } \\
\text { sistema analizado } \\
\text { ejecuta secuencias } \\
\text { reutilizables de tareas, } \\
\text { que son producto } \\
\text { de fenómenos de } \\
\text { emergencia. También se } \\
\text { utiliza para definir micro } \\
\text { secuencias integradas } \\
\text { que tienen una estructura } \\
\text { rígida que representan } \\
\text { algoritmos de } \\
\text { actividades individuales. }\end{array}$ \\
\hline
\end{tabular}




\section{DATOS DE LA PUBLICACIÓN}

\begin{tabular}{|c|c|c|c|c|c|c|c|}
\hline Autor & Año & & \multicolumn{3}{|c|}{ Nombre de la Investigación } & $\begin{array}{c}\text { Revista donde se ubica la } \\
\text { publicación }\end{array}$ & Volumen y número \\
\hline $\begin{array}{l}\text { Neubert, } \\
\text { Sebastian., } \\
\text { Göde, Bernd., } \\
\text { Gu, Xiangyu., } \\
\text { Stoll, Norbert., } \\
\text { Thurow, } \\
\text { Kerstin. }\end{array}$ & $(2017)$ & \multicolumn{4}{|c|}{$\begin{array}{l}\text { Potential of Laboratory Execution Systems (LESs) to } \\
\text { Simplify the Application of Business Process Management } \\
\text { Systems (BPMSs) in Laboratory Automation. } \\
\text { Potencial de los sistemas de ejecución de laboratorio (LES) } \\
\text { para simplificar la aplicación de los sistemas de gestión de } \\
\text { procesos de negocio (BPMS) en la automatización de } \\
\text { laboratorios. }\end{array}$} & $\begin{array}{l}\text { https://doi.org/10.1177/221106821 } \\
6680331 \\
\text { Revista: SLAS Technology }\end{array}$ & $\begin{array}{l}\text { Vol. 22, pp. } 206 \text { - 216, Abril, } \\
2017\end{array}$ \\
\hline \multicolumn{8}{|c|}{ CONTENIDO DE LA PUBLICACIÓN } \\
\hline $\begin{array}{l}\text { Tipo y Diseño de } \\
\text { Investigación }\end{array}$ & \multicolumn{2}{|c|}{$\begin{array}{l}\text { Población y } \\
\text { Muestra }\end{array}$} & Instrumentos & $\begin{array}{l}\text { Aspectos } \\
\text { éticos }\end{array}$ & & Resultados & Conclusión \\
\hline $\begin{array}{l}\text { Diseño: } \\
\text { Descriptivo. } \\
\text { Tipo: } \\
\text { Comparativo. }\end{array}$ & \multicolumn{2}{|c|}{$\begin{array}{l}\text { Modelo de } \\
\text { laboratorio de } \\
\text { Alemania. }\end{array}$} & $\begin{array}{l}\text { Guía de análisis } \\
\text { de datos. }\end{array}$ & No refiere. & \multicolumn{2}{|c|}{$\begin{array}{l}\text { Los sistemas de automatización de laboratorios se } \\
\text { centran en la combinación de instrumentos, estaciones } \\
\text { de trabajo y sistemas integrados con sistemas de } \\
\text { automatización complejos, la implementación de } \\
\text { soluciones de transporte móvil flexibles para cubrir } \\
\text { caminos, incluidas las puertas y ascensores, entre los } \\
\text { dispositivos y sistemas, el uso de robot y tecnologías } \\
\text { de información; mejora la observación de procesos } \\
\text { laboratorio, en comparación con las soluciones de } \\
\text { fabricación es bajo y rentable. }\end{array}$} & $\begin{array}{l}\text { La gestión de procesos de } \\
\text { negocio se encuentran } \\
\text { estrechamente relacionadas } \\
\text { con la automatización del } \\
\text { laboratorio, para una } \\
\text { estructuración jerárquica y } \\
\text { poder elaborar cadenas de } \\
\text { procesos con ciclos de vida } \\
\text { cortos y control de flujo de } \\
\text { material eficiente } \\
\text { incrementara la producción } \\
\text { en la organización. }\end{array}$ \\
\hline
\end{tabular}

Ciencia Latina Revista Científica Multidisciplinar, Ciudad de México, México. ISN 2707-2207 / ISSN 2707-2215 (en línea), julio-agosto, 2021, Volumen 5, Número 4. https://doi.org/10.37811/cl_rcm.v5i4.772 p.6322 


\section{DATOS DE LA PUBLICACIÓN}

\begin{tabular}{|c|c|c|c|c|}
\hline Autor & Año & Nombre de la Investigación & $\begin{array}{c}\begin{array}{c}\text { Revista donde se ubica la } \\
\text { publicación }\end{array} \\
\end{array}$ & Volumen y número \\
\hline $\begin{array}{l}\text { Cabanillas, } \\
\text { Cristina., } \\
\text { Resinas, } \\
\text { Manuel., Ruiz } \\
\text { Cortés, } \\
\text { Antonio. }\end{array}$ & $(2018)$ & $\begin{array}{l}\text { A template based approach for responsibility management } \\
\text { in executable business processes. } \\
\text { Un enfoque basado en plantillas para la gestión de } \\
\text { responsabilidades en procesos comerciales ejecutables. }\end{array}$ & $\begin{array}{l}\text { https://doi.org/10.1080/17517575.2 } \\
017.1390166 \\
\text { Revista: Enterprise Informatión } \\
\text { Systems }\end{array}$ & $\begin{array}{l}\text { Vol. } 12, \text { pp. } 550-586 \text {, } \\
\text { Mayo, } 2018\end{array}$ \\
\hline
\end{tabular}

\begin{tabular}{|c|c|c|c|c|c|}
\hline \multicolumn{6}{|c|}{ CONTENIDO DE LA PUBLICACIÓN } \\
\hline $\begin{array}{l}\text { Tipo y Diseño de } \\
\text { Investigación }\end{array}$ & $\begin{array}{c}\text { Población y } \\
\text { Muestra }\end{array}$ & Instrumentos & $\begin{array}{c}\text { Aspectos } \\
\text { éticos }\end{array}$ & Resultados & Conclusión \\
\hline $\begin{array}{l}\text { Diseño: } \\
\text { Descriptivo. } \\
\text { Tipo: } \\
\text { Comparativo. }\end{array}$ & $\begin{array}{l}\text { Modelo de casos } \\
\text { de España }\end{array}$ & $\begin{array}{l}\text { Guía de análisis } \\
\text { de datos. }\end{array}$ & No refiere. & $\begin{array}{l}\text { Metamodelo basado en matrices de asignación de } \\
\text { responsabilidad y un mecanismo flexible basado en } \\
\text { plantillas que transforma automáticamente dicha } \\
\text { información en elementos. Proceso comercial } \\
\text { automatizado para que el trabajo se realice en el } \\
\text { momento adecuado por el recurso adecuado. }\end{array}$ & $\begin{array}{l}\text { Las organizaciones } \\
\text { orientadas a procesos } \\
\text { gestionan los diferentes } \\
\text { tipos de } \\
\text { responsabilidades que } \\
\text { pueden tener sus } \\
\text { empleados } \\
\text { respecto a todas las } \\
\text { actividades que se } \\
\text { desarrollan a diario; } \\
\text { tienen en cuenta el } \\
\text { tiempo de ejecución de } \\
\text { la actividad } \\
\text { encomendada para } \\
\text { medir la eficiencia y } \\
\text { eficacia del proceso. }\end{array}$ \\
\hline
\end{tabular}




\section{RESULTADOS Y DISCUSIÓN}

El propósito de los proyectos de inversión de infraestructura, es incrementar el desarrollo económico, teniendo en cuenta los efectos de los precios como un factor importante en la diferencia entre eficiencia social y comercial (Suslov, Novikoba, \& Gulakova, 2021). La gestión de proyectos de desarrollo de infraestructura vial es fundamental, porque se ha tomado como una oportunidad de inversión viable y sostenible (Sai \& Arora, 2019). Así mismo la sostenibilidad no es solo una cuestión de despliegue técnico de los enfoques, sino también un proceso integrado de toma de decisiones; por lo tanto, para mejorar la efectividad, no solo deben avanzarse los enfoques, sino que también deben identificarse los procesos y las barreras contextuales (Suprayoga, Bakker, \& Spit, 2020). Los diseñadores de políticas han, facilitado una transición hacia un sistema de transporte más sostenible porque han implementado cargos por congestión vehicular de viajes en automóvil, han avanzado sistemas de transporte público y han mejorado la infraestructura para caminar y andar en bicicleta, están en la lista de ciudades inteligentes, con criterios que incluyen los sistemas de transporte público y la disponibilidad de servicios de transporte compartido (Petterson, Stjernborg, \& Curtis, 2021). Los enfoques de proyectos de inversión vial muestran un impacto significativo en la mejora de la sostenibilidad en proyectos viales apoyados con herramientas y técnicas de gestión de valor (Latif \& Chazali, 2019). Por otro lado, la inversión en mantenimiento y conservación de carreteras tiene un impacto positivo en la sociedad, más allá de prevenir el deterioro de la infraestructura y prolongar su vida útil, aportando el valor agregado de un sistema de transporte más seguro y sostenible (Calvo, Navarro, \& De Oña, 2020). De acuerdo al nivel de inversión en infraestructura vial se da de forma estratégica agrupándose entre ellos, pero teniendo en cuenta el nivel de desarrollo económico, la distancia geográfica y el comercio bilateral son los principales factores que han influido en la formación del patrón de la red de inversión regional (He \& Cao, 2019). Los modelos de financiación de proyectos viales son en mayoría construidas con la inversión pública, pero a su vez se han identificado tres problemas como fuentes potenciales de insostenibilidad, como la incertidumbre de los ingresos del proyecto a largo plazo, las restricciones presupuestarias proporcionadas por el gobierno y el apoyo gubernamental inadecuado para la adquisición de tierras donde se construirán las infraestructuras viales (Sihombing, Latief, Rarasati, \& Wibowo, 
2018). Según, el modelo dinámico regional en las regiones con una alta participación de las principales inversiones en infraestructura de carreteras por inversores privados y públicos, en el caso del primero, la falta de inversión conduciría a una disminución relativamente significativa del producto bruto interno PIB real o del empleo promedio y en el caso del segundo, el impacto de las grandes inversiones en infraestructura vial es casi insignificante (Rokicki, Haddad, Horridge, \& Stepniak, 2021). Por ende, implementar la gestión eficiente de la inversión de vías públicas mejora las propiedades de consumo de los corredores de transporte internacionales y nacionales (Slavinska, Stozhka, Kharchenko, Bubela, \& Kvatadze, 2019). Es muy importante lograr la calidad de la infraestructura de transporte para elevar el nivel de competitividad y lograr el principal objetivo de los países de la Alianza del Pacifico (Cortés, 2018). Con un enfoque basado en procesos mejora los indicadores de evaluación de impacto según un programa de investigación de carreteras de acceso comunitario y transporte (Rust \& Sampson, 2020).

En tal sentido los encuentros y desencuentros que existen son, los efectos del precio en la inversión de la infraestructura incrementan el desarrollo económico, pero se realizan a nivel macroeconómico y regional, hasta alcanzar el nivel microeconómico, la eficiencia social del proyecto se mide con la efectividad de la inversión del estado y la comercial con la duplicidad del rendimiento de los recursos existentes. La gestión de proyectos de infraestructura vial se ha considerado en los últimos tiempos como una de los pilares para el desarrollo, pero presentan vulnerabilidad porque esto repercute en los manejos políticos de los gobernantes de turno, que son los que aprueban el financiamiento público. En consecuencia, la sostenibilidad vial conocido también como verde, es dar las mismas oportunidades a la economía, el medio ambiente y la sociedad, lo ideal es generar un ciclo de armonía, pero esto no siempre se da debido a que cuando se realiza una infraestructura vial siempre se va a dañar el medio ambiente por más que se tomen las precauciones y se tenga un plan de impacto ambiental para mitigar estos daños ocasionados a la naturaleza. Los diseñadores de políticas de sistema de transporte más sostenible son conscientes de la imposibilidad de satisfacer la demanda de transporte por carretera, la población acepta vivir con congestión en las grandes ciudades o, alternativamente, lo vieron como un medio para el cambio modal del automóvil al transporte público y al ciclismo. Las controversias políticas y la aceptación 
pública de las medidas para disminuir el uso del automóvil son un desafío adicional, porque es un mal necesario. Los proyectos de inversión y la gestión de valor buscan la participación de todos los grupos de interés como la participación del estado, sociedad, Ministerios, gobiernos regionales, gobiernos locales, empresarios, contratistas y proveedores, se requiere que desempeñen sus roles y tomen las acciones necesarias para para garantizar el éxito de la construcción sostenible. La inversión en mantenimiento y conservación de carreteras, es difícil de realizar debido a que el presupuesto asignado para este rubro es bajo, los entes encargados no cuentan con los equipos de la maquinaria pesada y si lo cuentan no tienen el financiamiento, otro punto es que construir más vías y que estas se encuentren en perfecto estado no significa que se disminuya la letalidad, porque esto va a depender del nivel de cultura de los usuarios. El nivel de inversión en infraestructura vial se da de forma estratégica porque se muestra características comerciales de internalización regional entre países. De acuerdo a los modelos de financiación de proyectos viales son en mayoría construidas con la inversión pública, pero se han identificado tres problemas como fuentes potenciales de insostenibilidad, como la incertidumbre de los ingresos del proyecto a largo plazo, las restricciones presupuestarias proporcionadas por el gobierno y el apoyo gubernamental inadecuado para la adquisición de tierras donde se construirán las infraestructuras viales. Según, el modelo dinámico regional el impacto positivo de la inversión en infraestructura de transporte sobre la accesibilidad general es incuestionable, pero esto no es un indicador del desarrollo económico de determinadas regiones. La gestión eficiente de la inversión de vías públicas es el desarrollo del conjunto de herramientas para el análisis técnico y la evaluación monetaria de los activos de transporte por carretera existentes. Por ende, lograr la excelencia de la red vial para elevar el nivel de competitividad, se ve obstaculizada por los precios de peajes, valor de combustible, importes financieros, devaluación, autorizaciones, permisos, mientras que no exista una regulación y, a pesar que se destinan grandes presupuestos de inversión en la red vial. Un enfoque basado en procesos mejora la innovación para generan crecimiento en el sector de la construcción vial.

En cuanto a los hallazgos de la mejora de procesos de gestión, para los principales líderes de una organización se reflejan en un manejo eficiente del tiempo; basado en un esfuerzo en equipo donde se incluyan a los expertos con capacidad de critica y 
decisiones, a la vez que procura un proceso de mejora continua para la atención al público (Medina, Nogueira, Hernández, \& Comas, 2019). La gestión de procesos para una sociedad sostenible, se basa en la seguridad ambiental (Waris, y otros, 2019). Según Waris, Panigrahi, Mengal, Soomro, Mujeeb, Mirjat, Ullah, Azlan y Khan (2019), el enfoque de los procesos da sostenibilidad a la industria de la construcción y se inclina más hacia la selección de materiales, el diseño de estructuras y el reciclaje de materiales que las preocupaciones ambientales como tal, evidentemente, existe una brecha entre la evaluación del enfoque convencional de selección de equipos y la inclusión del concepto de sustentabilidad en la elección de varias alternativas durante la fase de adquisición de un estudio. En el desarrollo sostenible se debe incluir al género femenino en los procesos y resultados de los programas de inversión, el transporte es un factor clave para el logro de un nivel alto de objetivos en los países en desarrollo (Njenga \& Tanzarn, 2020). Los modelos de los procesos de riesgos críticos en proyectos contribuyen al desarrollo y la sostenibilidad de los proyectos de las carreteras (Zheng, Yuan, Li, \& Skibniewski, 2019). La tecnología de la información de procesos para mejorar la gestión es un punto clave, se apoya en mejores experiencias para los usuarios (internos y externos), aumenta la satisfacción y los ingresos de la empresa (Sánchez, 2021). El Motor de la gestión de procesos ejecuta secuencias reutilizables de tareas, para salvaguardar los casos de emergencia que atraviesa una empresa (Koryl \& Mazur, 2017). Se encuentran estrechamente relacionadas con la automatización de procesos, para una estructuración jerárquica y poder elaborar cadenas de procesos con ciclos de vida cortos y control de flujo de material eficiente que incrementara la producción en la organización (Neubert, Gode, Gu, Stoll, \& Thurow, 2017). Las organizaciones orientadas a procesos gestionan los diferentes tipos de responsabilidades que pueden tener sus empleados con respecto a todas las actividades que se desarrollan a diario; tienen en cuenta el tiempo de ejecución de la actividad encomendada para medir la eficiencia y eficacia del proceso (Cabanillas, Resinas, \& Ruiz, 2018).

En tal sentido los encuentros y desencuentros que existen son, la gestión por procesos es una labor ardua, por años las organizaciones notables y cruciales han presentado una estructura funcional, resistiéndose al cambio en la mayoría de las entidades para la implementación de la gestión por procesos, y que resultan ser los encargados de realizar 
la transición y la integración de valor se ha vuelto hoy en día una clave de dirección estrategia de las instituciones.

Los procesos industriales utilizados por empresas responsables y competitivas deben incorporar diseño en pasos de eficiencia, el concepto de sostenibilidad está involucrado en un proceso en el que podemos obtener mejores indicadores con menos recursos, estos procesos deben apoyar el desarrollo sustentable, garantizando las necesidades básicas de la sociedad, con el adecuado uso del medio ambiente, y sin comprometer la sustentabilidad de las sociedades futuras. El enfoque de los procesos de sostenibilidad está destinado a tener en cuenta una lista de factores tangibles e intangibles como el costo, la capacidad, la productividad y la eficiencia. La participación del género femenino es muy importante en los procesos y resultados de los programas de inversión. Los procesos de riesgos críticos es una estrategia de transformación para la infraestructura vial. Acompañado con los procesos de las tecnologías de la información mejoran la calidad de los servicios de la empresa. Surgen grandes limitaciones en la capacidad de control de procesos, nuevos tipos de sistemas de flujo de trabajo que normalmente funcionan de una manera más ágil, siguiendo el enfoque de razonamiento basado en casos. Las tareas de transporte entre las ejecuciones de procesos de las islas de automatización en las empresas traen consigo la optimización de recursos. Y para gestionar las responsabilidades designadas con las diferentes actividades basados en sus procesos para un desempeño basado en el tiempo, lo que requiere decir que mucho tiempo que se toma en una actividad esta propenso a errores.

\section{CONCLUSIÓN O CONSIDERACIONES FINALES}

Las inversiones en la infraestructura vial incrementan el desarrollo económico, pero se realizan a nivel nacional, regional y local; dependen de la eficiencia social del proyecto y se mide con la efectividad de la inversión del estado. Es vital la gestión de proyectos de infraestructura vial porque es uno de los pilares para el desarrollo, pero presentan vulnerabilidad por la actitud en los manejos políticos de los gobernantes de turno, que aprueban el financiamiento público. Para alcanzar la sostenibilidad vial es dar las mismas oportunidades a la economía, el medio ambiente y la sociedad. De acuerdo a las políticas de sistema de transporte más sostenible son conscientes de la imposibilidad de satisfacer la demanda de transporte por carretera, pero buscaron alternativas como el transporte público y el ciclismo. Existen controversias políticas para la aprobación 
pública de la disminución del uso del automóvil, porque sería un mal necesario para la sociedad. Los proyectos de inversión y la gestión de valor buscan la participación de todos los grupos de interés, para que tomen las acciones necesarias y garantizar el éxito de la construcción sostenible. Garantizar la inversión en mantenimiento y conservación de carreteras, es difícil de realizar debido a que el presupuesto asignado para este rubro es bajo. El grado de inversión en infraestructura vial se da de forma estratégica, teniendo en cuenta las relaciones comerciales internacionales y regionales entre países. Los presupuestos de proyectos viales en su mayoría son construidos con la inversión pública del estado, pero corren riesgos de no llegar a concluirse en los plazos establecidos debido a la demora de los ingresos de financiamiento y otros factores sociales como el uso de servidumbre viales que se encuentran en zonas privadas. Los desarrollos económicos son graduales en las regiones y tienen un impacto positivo con la inversión en infraestructura de transporte. Para lograr la eficiencia de la red vial y el nivel de competitividad, pero a veces la calidad se ve truncada debido a que existe poca regulación en los permisos, licencias, y gastos operativos.

La gestión por procesos es una exigencia de alineación a la estrategia que buscan la transformación y la incorporación de valor de las organizaciones. Esto se da con la implementación de los procesos en las instituciones responsables y competitivas para obtener la eficiencia y la sostenibilidad de las sociedades futuras. Teniendo en cuenta una lista de factores tangibles e intangibles como el costo, la capacidad, la productividad y la eficiencia. Así mismo es muy poca la participación femenina en los procesos y resultados de los programas de inversión. Teniendo en cuenta los procesos de riesgos críticos como estrategia para lograr el cambio de la infraestructura vial. Usando la tecnología en los procesos para lograr la excelencia de los servicios de la empresa. Los procesos de automatización en las empresas traen consigo la optimización de recursos. Asignado responsabilidades de las diferentes actividades basados en sus procesos mejorando el desempeño periódico requerido y que no esté propensa a errores.

Faltan cerrar las brechas de los proyectos de infraestructura vial y la implementación de los procesos en la organización, por la cual se necesita del compromiso de todos los grupos de interés.

Se recomienda realizar gestiones de proyectos de inversión pública de infraestructura vial, para mejorar el desarrollo económico, calidad de servicio, eficiencia y efectividad 
de los habitantes. Así mismo alcanzar la sostenibilidad vial y satisfacer la demanda de transporte por carretera, obteniendo las mismas oportunidades económicas, ambientales y sociales. Establecer un plan de acciones estratégicas para reducir el uso del automóvil, por medio de incentivos de renovar, sensibilizaciones, capacitaciones, motivación, con el objetivo de realizar un cambio y bajar los niveles de contaminación ambiental como gases y ruidos. Con el trabajo en equipo de los grupos de interés y lograr el éxito de la construcción sostenible. Por otro lado, gestionar la inversión en mantenimiento y conservación de carreteras, porque con ello aseguramos la conservación y el periodo de vida útil de las vías. Aplicar estrategias para mejorar el plan vial de las ciudades, con el comercio, turismo, productividad estableciendo relaciones internacionales y regionales entre países vecinos. Gestión del incremento de los presupuestos en los proyectos viales para realizar mas obras y acortar las brechas que existe en la infraestructura vial. Gestionar que las partidas presupuestales sean distribuidas equitativamente para lograr el desarrollo económico igualitario en todas las regiones. Mejorar la eficiencia de la infraestructura vial para incentivar la competitividad ciudadana.

Se recomienda la implementación de mejoras de procesos para la generación de cambios en la agilización de los procesos de las organizaciones. Gestionar los procesos para incrementar el valor de las organizaciones. Establecer los procesos en las instituciones responsables y competitivas con el fin de obtener la eficiencia y la sostenibilidad de las sociedades futuras. Es importante incrementar la participación de las mujeres en los procesos de los programas de inversión. Desarrollar un plan de acciones de los procesos de riesgos críticos como estrategia para lograr el cambio de la infraestructura vial. Usar la tecnología en los procesos de la empresa. Las gestiones de procesos optimizan los recursos de la empresa. Se deben designar responsabilidades de las actividades basados en procesos para mejorar el desempeño de las instituciones.

Se recomienda realizar gestiones para cerrar las brechas de los proyectos de inversión pública en la infraestructura vial con la implementación de las mejoras de los procesos en la organización, con el único fin de mejorar el servicio y el bienestar de los ciudadanos, para lograrlo se necesita del compromiso y participación de todos los grupos de interés.

\section{REFERENCIAS BIBLIOGRAFICAS}


Abad, E., Morales, E., Cortés, F., \& Belmonte, L. (Mayo de 2020). Industrial Processes Management for a Sustainable Society: Global Research Analysis. Processes, 8(631), 1-26. doi:https://doi.org/10.3390/PR8050631

Cabanillas, C., Resinas, M., \& Ruiz, A. (Mayo de 2018). A template based approach for responsibility management in executable business processes. Enterprise Informatión Systems, $\quad 12, \quad 550-586$. doi:https://doi.org/10.1080/17517575.2017.1390166

CAF- Banco de Desarrollo de América Latina. (1 de Diciembre de 2020). CAF Apoya al Perú con Intervenciones en $9.150 \mathrm{~km}$ de Vías en las Provincias y Recursos para Atender los Efectos de la Pandemia. Obtenido de hhttps://www.caf.com/es/actualidad/noticias/2020/12/caf-apoya-al-peru-conintervenciones-en-9150-km-de-vias-en-las-provincias-y-recursos-para-atenderlos-efectos-de-la-pandemia/?parent $=6444$

Calvo, F., Navarro, J., \& De Oña, J. (Agosto de 2020). Road investment and traffic safety: An international study. Sustainability (Switzerland), 12(6332), 1-15. doi:https://doi.org/10.3390/SU12166332

Cortés, R. (Julio - Diciembre de 2018). ¿Qué tan competitivos son los países miembros de la Alianza del Pacífico en infraestructura de transporte? EAN(85), 143-162. doi:https://doi.org/10.21158/01208160.n85.2018.2055

Gestión. (15 de 01 de 2021). Gobierno apunta a que inversión pública crezca 35\% este año: ¿Es factible y cómo puede concretarse? Obtenido de https://elcomercio.pe/economia/peru/infraestructura-gobierno-apunta-a-queinversion-publica-crezca-35-este-ano-es-factible-y-como-puede-concretarsemef-waldo-mendoza-ncze-noticia/?ref=ecr

Gobierno Regional de San Martín. (2012-2021). Plan Víal Departamental Participativo de la Región San Martín 2012-2021. MOYOBAMBA, SAN MARTÍN. Obtenido de https://www.regionsanmartin.gob.pe/OriArc.pdf?id=67514

He, Q., \& Cao, X. (Setiembre de 2019). Pattern and influencing factors of foreign direct investment networks between countries along the "belt and road" regions. $\begin{array}{lrrr}\text { Sustainability } & \text { (Switzerland), } & \text { 11(4724), }\end{array}$ doi:https://doi.org/10.3390/su11174724 
Koryl, M., \& Mazur, D. (Junio de 2017). Towards emergence phenomenon in business process management. Archives of Control Sciences, 27, 263-277. doi:https://doi.org/10.1515/acsc-2017-0017

Latif, M., \& Chazali, Z. (Abril de 2019). Value management / value engineering (VM/VE) application in Malaysian public construction projects: Application of VM/VE study improved roads project sustainability. IOP Conference Series: Materials Science and Engineering, 512(012046), 1-12. doi:https://doi.org/10.1088/1757-899X/512/1/012046

Medina, A., Nogueira, D., Hernández, A., \& Comas, R. (2019). Procedimiento para la gestión por procesos: métodos y herramientas de apoyo. Ingeniare. Revista chilena de ingeniería, 27(2), 328-342. doi:https://doi.org/10.4067/S071833052019000200328

MEF. (28 de Julio de 2019). Plan Nacional de Infraestructura para la Competitividad. El Peruano, págs. 1-64. Obtenido de https://cdn.www.gob.pe/uploads/document/file/348761/DS238_2019EF.pdf

MEF. (2021). Portal de Transparencia Económica - Consulta Amigable. Lima, Perú: MEF. Obtenido de https://apps5.mineco.gob.pe/transparencia/mensual/default.aspx?y=2021\&ap= ActProy

Neubert, S., Gode, B., Gu, x., Stoll, N., \& Thurow, K. (Abril de 2017). Potential of Laboratory Execution Systems (LESs) to Simplify the Application of Business Process Management Systems (BPMSs) in Laboratory Automation. SLAS Technology, 22, 206-216. doi:https://doi.org/10.1177/2211068216680331

Njenga, P., \& Tanzarn, N. (Abril de 2020). Scaling up gender mainstreaming in transport: Policies, practices and monitoring processes. Proceedings of the Institution of Civil Engineers: Transport, 173, 64-75. doi:https://doi.org/10.1680/jtran.18.00152

Palacios, C. (2018). Efecto de la inversión pública en la infraestructura vial sobre el crecimiento de la economía peruana entre los años 2000-2016. Ingeniería Industrial, 1(36), 10. doi:https://doi.org/10.26439/ing.ind2018.n036.2454

PCM. (27 de Setiembre de 2018). Resolución de Secretaría de Gestión Pública Nº062018- PCM/SGP. Obtenido de Plataforma Digital del Estado Peruano: 
https://www.gob.pe/institucion/pcm/normas-legales/235944-006-2018-pcm$\operatorname{sgp}$

Petterson, F., Stjernborg, V., \& Curtis, C. (Junio de 2021). Critical challenges in implementing sustainable transport policy in Stockholm and Gothenburg. Cities, 113(103153), 1-10. doi:https://doi.org/10.1016/j.cities.2021.103153

Rokicki, B., Haddad, E., Horridge, J., \& Stepniak, M. (Abril de 2021). Accessibility in the regional CGE framework: the effects of major transport infrastructure investments in Poland. Transportatión, 48, 747-772. doi:https://doi.org/10.1007/s11116-019-10076-w

Rust, F., \& Sampson, R. (2020). A systems-based R\&D management model for the road and transport engineering sector applied to a community access roads and transport research programme. African Journal of Science, Technology, Innovation and Development, 12, 547-560. doi:https://doi.org/10.1080/20421338.2019.1640344

Sai, A., \& Arora, J. (Setiembre de 2019). Financial impediments to road infrastructure development in India. International Journal of Innovative Technology and Exploring Engineering, 8, 405-415. doi:https://doi.org/0.35940/ijitee.K1072.09811S19

Sánchez, J. (Mayo de 2021). Model to optimize the decision making on processes in it departments. $\quad$ Mathematics, $\quad$ 9(983), 1-23. doi:https://doi.org/10.3390/math9090983.

Serrano, J., \& García, R. (2017). La construcción de infraestructuras de transporte en España: compleja realidad territorial y devenir incierto. Finisterra, 52(106), 328. doi:http://dx.doi.org/10.18055/Finis10885

Sihombing, L., Latief, Y., Rarasati, A., \& Wibowo, A. (Mayo de 2018). Project financing models for toll road investments: A state-of-the-art literature review. Civil Engineering and Architecture, 6, 115-127. doi:https://doi.org/10.13189/cea.2018.060301

Slavinska, O., Stozhka, V., Kharchenko, A., Bubela, A., \& Kvatadze, A. (2019). Development of a model of the weight of motor roads parameters as part of the information and management system of monetary evaluation. Eastern European 
Journal of Enterprise Technologies, $1, \quad 46-59$. doi:https://doi.org/10.15587/1729-4061.2019.156519

Suprayoga, G., Bakker, M., \& Spit, T. (Diciembre de 2020). A systematic review of indicators to assess the sustainability of road infrastructure projects. European Transport Research Review, 12(19), 1-15. doi:https://doi.org/10.1186/s12544020-0400-6

Suslov, V., Novikoba, T., \& Gulakova, O. (2021). Ценовые аспекты оценки инвестиционных проектов. Economy of Región, 17, 16-30. doi:https://doi.org/10.17059/EKON.REG.2021-1-2

Waris, M., Panigrahi, S., Mengal, A., Soomro, M., Mirjat, N., Ullah, M., . . Khan, A. (2019). An Application of Analytic Hierarchy Process (AHP) for Sustainable Procurement of Construction Equipment: Multicriteria-Based Decision Framework for Malaysia. Mathematical Problems in Engineering, 2019(6391431), 1-20. doi:https://doi.org/10.1155 / 2019/6391431

Zheng, C., Yuan, J., Li, L., \& Skibniewski, M. (2019). Process Based Identification of Critical Factors for Residual Value Risk in China's Highway PPP Projects. Advances in Civil Engineering, 173(5958904), 1-21. doi:https://doi.org/10.1155/2019/5958904 